\title{
Global View of the Intraseasonal Oscillation during Northern Winter
}

\author{
HuANG-Hsiung Hsu \\ Department of Atmospheric Sciences, National Taiwan University, Taipei, Taiwan \\ (Manuscript received 14 April 1995, in final form 24 January 1996)
}

\begin{abstract}
In this study, SVD analysis is applied to a normalized 200-mb streamfunction/OLR covariance matrix to extract the most recurrent coupled pattern in the northern winter, after the removal of the climatological seasonal cycle and seasonal means for each winter. The first two singular vectors are on an intraseasonal timescale and the combination of the two forms an oscillation. It is characterized by eastward propagation in the Indian Ocean and the western Pacific, standing oscillations in both the Tropics and the extratropics, and the poleward propagation of a zonally symmetric structure.

Although there exists an eastwardly propagating pattern, the phase relationship between geopotential, wind, and streamfunction fields is inconsistent with that of equatorial Kelvin waves. Eastward propagation is most evident in the Tropics of the Southern Hemisphere, while the signals in the Northern Hemisphere are characterized by standing oscillations. The distinct characteristics of the Northern and Southern Hemisphere can be attributed to the different properties of the mean flows, which lead to distinct Rossby wave source distributions in the two hemispheres.

Abrupt developments of regional circulation anomalies are found in the exit regions of the Pacific and Atlantic jet streams. The one in the Pacific resembles the Pacific/North American pattern and develops in a process similar to the optimal excitation of the normal mode, by extracting barotropic energy from the mean flow. Similar energy conversion also occurs in the Atlantic. Both analyses of energy conversion and Rossby wave source indicate the occurrence of rigorous extratropical activity in the Northern Hemisphere, that is affected indirectly by tropical heating. The propagating circulations in the Southern Hemisphere, that resemble equatorial Rossby waves, could be the direct response to the tropical heating, while the signals of standing oscillation are the mixed results of direct response to the tropical heating and internal dynamics in the extratropics.

The results show the complexity of the intraseasonal oscillation, involving equatorial wave dynamics, tropicalextratropical interactions, and eddy-mean flow interactions. The phenomenon is global and it is inadequate to treat the problem as either a purely tropical phenomenon or a purely extratropical phenomenon.
\end{abstract}

\section{Introduction}

Intraseasonal oscillation in the Tropics has been studied intensively since its discovery by Madden and Julian $(1971,1972)$. Spectral analyses on various variables have been consistently finding spectral peaks with a nearly 40-50-day period, for example, Hartmann and Gross (1988), Nishi (1989), among others. Multivariate analyses such as principal component analysis has also been applied to global datasets to examine the spatial structure and time evolution of the intraseasonal oscillation, for example, Knutson and Weickmann (1987) and Lau and Chan (1985). The composite life cycle of the intraseasonal oscillation shown in Knutson and Weickmann (1987) exhibits a streamfunction pattern accompanied by either active or inactive largescale convective activity, which has a zonal scale equivalent to wavenumber one and propagates east-

Corresponding author address: Dr. Huang-Hsiung Hsu, Department of Atmospheric Sciences, National Taiwan University, 61, Ln144, Sec 4 Keelung Road, 10772 Taipei, Taiwan. ward from the Indian Ocean into the western Pacific. A close examination of their results does not clearly support the idea of an eastwardly propagating pattern around the globe, except in the velocity potential field. The outgoing longwave radiation pattern decays rather quickly when it reaches the date line. The slowly eastward moving streamfunction pattern also tends to stall in the eastern Pacific and is followed by the sudden development of a new pattern on a much larger zonal scale covering the southern Eurasian continent.

The discrepancy between the behavior of the velocity potential and other variables can be attributed to the oversmoothing effect of the inverse Laplacian operation on the divergence field. The centers of velocity potential do not necessarily correspond to the maximum divergence or convergence. Hsu et al. (1990) pointed out the inadequacy to interpret the evolution of the intraseasonal oscillation based on the velocity potential. They and Weickmann and Khalsa (1990) also found that the eastward movement of the pattern was not a smooth propagation with an almost constant speed. Instead, a sudden shift of the pattern may occur during the evolution. Besides the eastwardly propagat- 
ing signal, strong standing oscillations are also evident in the western Pacific, central Africa, and South America where active convection persists (e.g., in Hsu et al. 1990; Knutson and Weickmann 1987). The standing signals, which may play an important role in the evolution of intraseasonal oscillation, have received much less attention than they deserve in both empirical and theoretical studies.

Signals on an intraseasonal timescale are not restricted to the Tropics. Strong intraseasonal signals in the extratropics have been reported by several studies, for example, Lau and Phillips (1986), Ghil and Mo (1991a,b), Schubert and Park (1991), Hsu et al. (1990), among others. Lau and Phillips (1986) documented the time lag relationship between the extratropical wavetrains and tropical convection and suggested the coupling between the normal modes of the Tropics and the extratropics. Ghil and Mo (1991a) concluded that the extratropical stationary modes were not driven by the tropical convection and that the intraseasonal modes in the Tropics and the extratropics are two independent oscillators. They, however, suggested that the two oscillators are coupled by extratropical wavetrains. Schubert and Park (1991) found that the tropical convection in the western Pacific has a strong influence on the extratropical mode in the Pacific, by modifying the zonal wind distribution. Their extratropical mode, which was also documented by Hsu and Lin (1992), resembled the PNA (Pacific/North America) pattern (Wallace and Gutzler 1981) and was found to have an energy source in the extratropics. Therefore, the extratropical mode is not a wavetrain forced purely by tropical convection. In a case study, Hsu et al. (1990) also pointed out that the intraseasonal oscillation should not be seen as a purely tropical phenomenon and the tropical-extratropical interaction can play a key role in the time evolution of the oscillation.

Many theories have been proposed to explain the behavior of the tropical intraseasonal oscillation. Madden and Julian (1972) pointed out its similarity to the equatorial Kelvin wave because of the eastwardly propagating nature of the oscillation along the equator. The 40-50 day timescale is, however, much larger than the timescale of a dry Kelvin wave. Chang (1977) found that the inclusion of viscosity yielded a Kelvin mode with a timescale of 40-50 days. The Kelvin waveconditional instability of the second kind (CISK) mechanism, taking into account the nonlinear heating effect, has been proposed to explain the phenomenon by Lau and Peng (1987) and Chang and Lim (1988) among others. The mechanism, however, produces a timescale of 20-30 days, much shorter than the observed one. It also fails to offer a reasonable explanation for the passage of a Kelvin wave through the eastern Pacific where convective activity is weak. Sui and Lau (1989) included surface heat fluxes in their model to help sustain the wave in the eastern Pacific. However, the mechanism also shortens the timescale of the wave. Wang and Rui (1990) proposed a frictional wave-CISK mechanism that was supported by the recent studies of Salby et al. (1994) and Hendon and Salby (1994). Emanuel (1987) and Neelin et al. (1987) proposed an evaporation-wind feedback mechanism, that strongly depends on the basic state, to explain the eastward propagation. In the real atmosphere, surface westerlies prevail in the Indian Ocean and the western Pacific where intraseasonal oscillations exhibit the strongest signals. Such a basic state does not favor an eastward propagation.

The above theories were designed to explain the eastward propagation of the tropical oscillation, that is most evident in the velocity potential field but is not as clear in other fields, such as streamfunction, divergence, or outgoing longwave radiation (OLR). What is more important, Kelvin-wave-like structures associated with intraseasonal oscillation have not been well documented except in the velocity potential field. Hsu et al. (1990) found little evidence of an equatorial Kelvin wave in the 1985/86 intraseasonal oscillation events. Hendon and Salby (1994) documented the circulations of intraseasonal oscillation that exhibited characteristics similar to those of equatorial Kelvin waves, by considering only the eastward, wavenumber 1-3 signals. However, the observed amplitudes of the equatorial winds do not drop away from the equator as rapidly as the simulated tropical circulations do in a theoretical study by Salby et al. (1994). It seems likely that the circulations extracted by Hendon and Salby (1994) contained much more information than just equatorial waves.

Moreover, the theories are unable to explain the strong signals of standing oscillations. Theories explaining the existence of the standing oscillations have been proposed recently. For example, $\mathrm{Hu}$ and Randall (1994) suggested that an intraseasonal oscillation could occur locally because of the interaction of the radiative and convective processes, without considering the planetary-scale circulation. In a study by Bladé and Hartmann (1993), local instability recurs on a timescale of 40 days, without the initiating effect of moist Kelvin waves as proposed in the Kelvin waveCISK theory. The timescale of local oscillation depends on the growth and duration times of the convective episode together with the recharge time for the instability.

Theories based on tropical dynamics alone are not able to explain the existence of the extratropical mode and its coupling with the tropical convection. The recent development in the instability theory may shed light on the tropical-extratropical interaction. The observed extratropical intraseasonal signals exhibit a structure resembling that of the most unstable normal mode in a barotropic model, incorporating a zonally varying climatological basic state. It was demonstrated by Simmons et al. (1983), using a barotropic model, that the prescribed divergence forcing in India and In- 
dochina results in the largest response of a circulation structure resembling the most unstable normal mode. The results are consistent with the finding of the adjoint mode, which is a wavelike pattern over India and Indochina and leads to the optimal excitation of the normal mode (e.g., Zhang 1988; Ferranti et al. 1990). The growth of the PNA-like structure through barotropic energy conversion from the mean flow is consistent with the finding of Schubert and Park (1991). Both theoretical and empirical results discussed above indicate the importance of the tropical-extratropical interaction in an intraseasonal oscillation. The tropical convection may not be responsible for the growth of the extratropical mode, but may trigger the initiation of the mode.

In most of the previous empirical studies, the intraseasonal oscillations were often extracted from the velocity potential field, emphasizing the propagating feature. The importance of the standing oscillation and the extratropics has not been the focus of much discussion. The development of theories has accordingly emphasized the importance of the equatorial Kelvin wave, viewing the phenomenon as a purely tropical feature. In this paper, we shall investigate the phenomenon on a global perspective, demonstrating the importance of extratropical circulation compared to the equatorial waves. This study applies the singular value decomposition method to the combined streamfunction/OLR covariance matrix to extract the most important coupled mode for a reexamination of the life cycle of intraseasonal oscillation. Section 2 describes the dataset and the analysis procedure. The time evolution of the OLR and the streamfunction patterns are reviewed in section 3. Section 4 discusses the existence of the Kelvin wave-like structure in the intraseasonal oscillation and section 5 examines the relative importance of standing oscillations and zonally propagating features. Distribution and evolution of Rossby wave source are shown in section 6 to examine the divergent effect on rotational flow. An extratropical structure and its development associated with the standing oscillation are discussed in section 7 . There exist zonally symmetric patterns in the intraseasonal oscillation that are presented in section 8. Finally, the conclusions are given in section 9 .

\section{Data and analysis procedures}

The data used in this study are the European Centre for Medium-Range Weather Forecasts (ECMWF) initialized wind and geopotential height data at 200, 850, and $1000 \mathrm{hPa}$ and outgoing longwave radiation (OLR) at 1200 UTC for eight winters (defined as December, January, and February) from 1980/81 to $1987 / 88$. The ECMWF data are on a $5^{\circ} \times 5^{\circ}$ global grid and the OLR data are on a $5^{\circ} \times 5^{\circ}$ grid between $40^{\circ} \mathrm{N}$ and $40^{\circ} \mathrm{S}$. To emphasize the large-scale structure, the OLR, divergence and vorticity fields were spatially smoothed us- ing a T12 spectral filter proposed by Sardeshmukh and Hoskins (1984). A climatological mean seasonal cycle and the seasonal mean for each winter were subtracted to remove a part of interannual variability and to reduce the influence of the changes in the ECMWF data assimilation system through the years. We then computed five-day running means to remove the high-frequency variability.

Singular value decomposition (SVD) analysis as described in Bretherton et al. (1992) was then applied to the temporal covariance matrix between the normalized streamfunction at $200 \mathrm{hPa}$ and the normalized OLR to retrieve the most recurrent coupled patterns. The direct outputs of SVD analysis include: 1) singular vectors describing spatial patterns, 2) expansion coefficients describing the temporal variation of singular vectors, and 3 ) singular values representing the amount of variance explained by singular vectors. The singular vectors obtained in this way are essentially the homogeneous correlation maps named by Bretherton et al. (1992) that are the simultaneous correlation maps between the expansion coefficients and the corresponding fields. Instead of showing the singular vectors, maps of lag correlation coefficient, between the expansion coefficients of the first two OLR vectors and the various variables, at various time lags were computed to examine the corresponding time evolution and spatial structures. The same analysis procedures were also applied to a 30-60 day bandpass filtered dataset to examine the influence of higher and lower frequency variability on the results derived from 5-day mean data. The comparison indicates a consistency between the results derived from the two datasets. The results derived from the 5-day means will be shown here.

To test the significance of correlation coefficients between the expansion coefficients and the various fields, degrees of freedom (DOF) were estimated following the procedure used in Chen (1982). We examined the spatial distribution of the DOF for each correlation map and found the smallest number of the DOF to be around 60 . For the sake of convenience, 60 degrees of freedom will be assumed for each grid point in every correlation map. To reject the null hypothesis of no correlation at the 0.02 and 0.05 significance levels using a two-tailed test, correlation coefficients have to be at least 0.3 and 0.25 , respectively.

\section{Time evolution of singular vector}

The first and second singular vectors explain 36\% and $12 \%$ of the squared covariance of the combined normalized 200-hPa streamfunction/OLR covariance matrix, respectively. Time series of the expansion coefficients associated with the first two singular vectors are shown in Fig. 1. They are characterized by strong intraseasonal variability. Higher frequency signals are also present in Fig. 1 because only a climatologicalmean seasonal cycle and the seasonal means for each 
(a) OLR

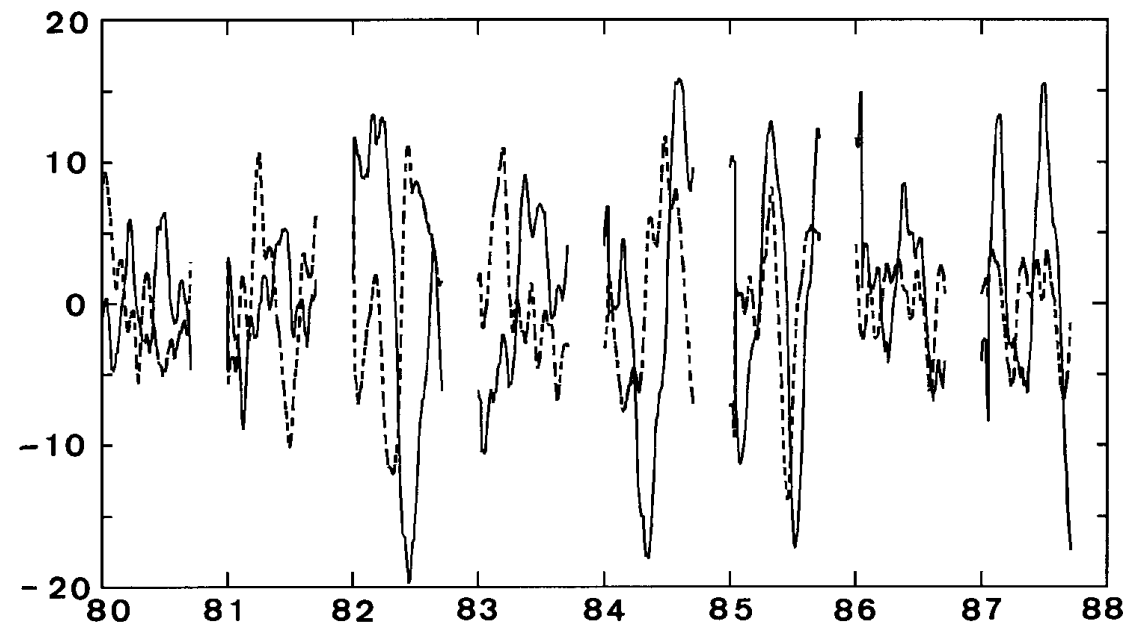

(b) 200 hPa $\psi$

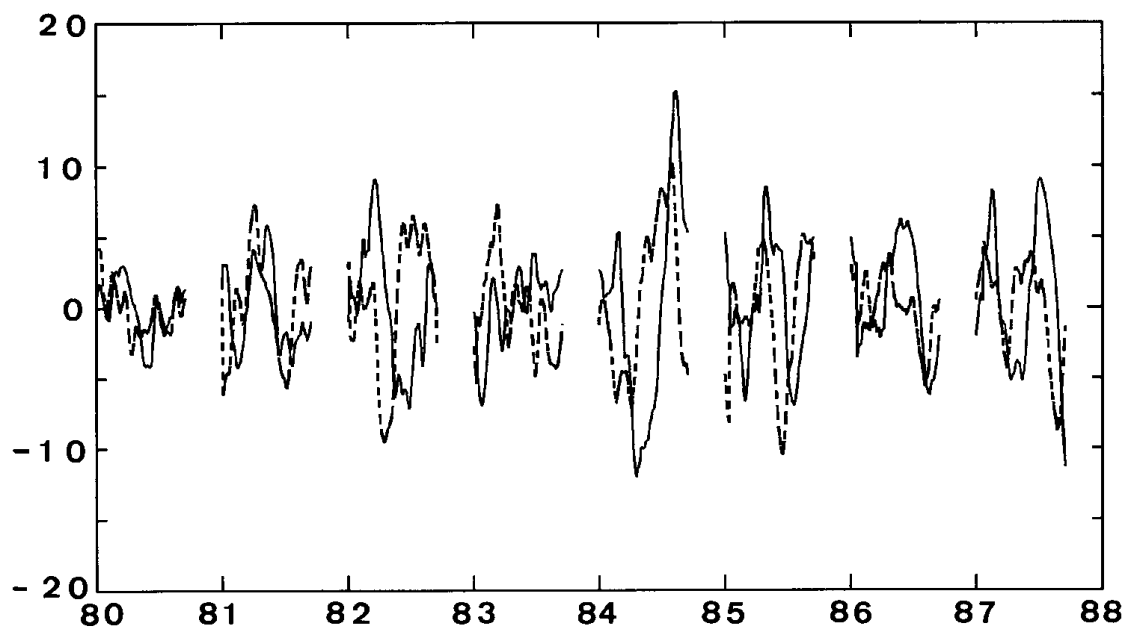

FIG. 1. The expansion coefficients for the (a) OLR and (b) 200-hPa streamfunction vector of the first (solid line) and second (dashed line) mode for each winter from 1980/81 to 1987/88.

northern winter were subtracted from the five-day running means. The first two singular vectors in this study tend to be in quadrature in both time and space. An examination of the two time series presented in Fig. 1 indicates that the second vector tends to lead the first vector by a quarter of a cycle.

Lag correlation maps from -15 day lag to 15 day lag are shown in Fig. 2 to illustrate the time evolution of the first OLR and 200-hPa streamfunction vectors. The simultaneous correlation map (i.e., day 0, Fig. $2 \mathrm{~d}$ ) is identical to the first OLR and 200-hPa streamfunction singular vectors obtained from SVD analysis, while the correlation map for 15-day lag (i.e., day 15, Fig. $2 \mathrm{~g}$ ) corresponds to the second set of singular vectors but with reversed signs. If stringent filtering had been applied to isolate the 30-60 day oscillation, the patterns at day -15 should just be the mirror image of the patterns at day 15. In this study, the similarity between the patterns at day -15 and day 15 is marked. However, there are differences between the two because of the presence of signals whose period is not 30-60 days. Since the first two vectors have a phase lag of a quarter of cycle, we shall show only the lag correlation maps for the first vector. For the sake of convenience, the features shown in the correlation maps will be described as if the expansion coefficients are positive. For example, negative (positive) correlation coefficients for the 


\section{(a) day -15}

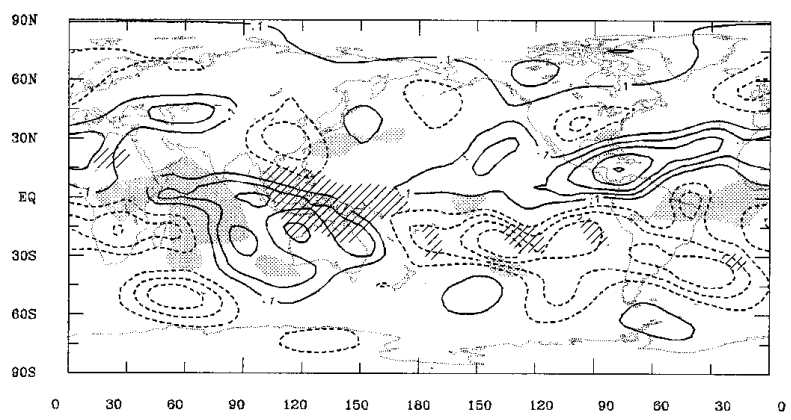

(b) day $-\mathbf{1 0}$

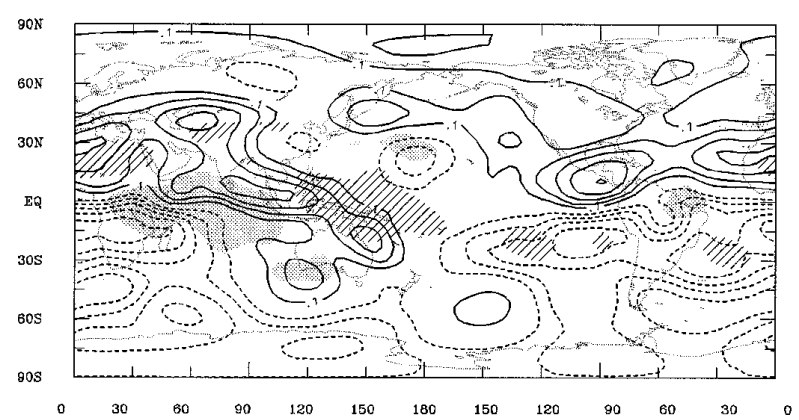

(c) day -5

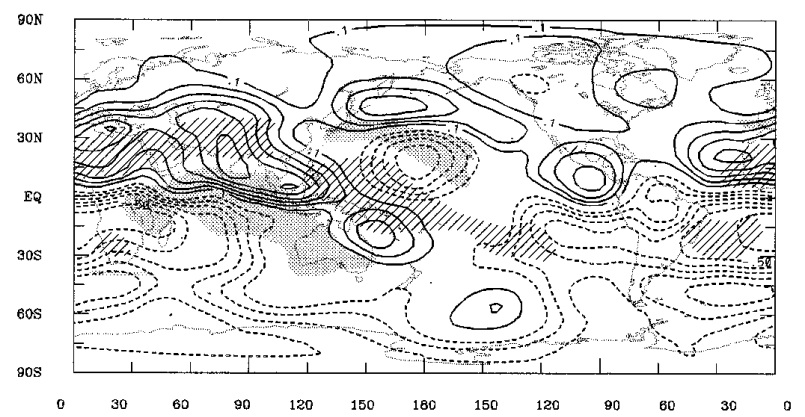

(d) day 0

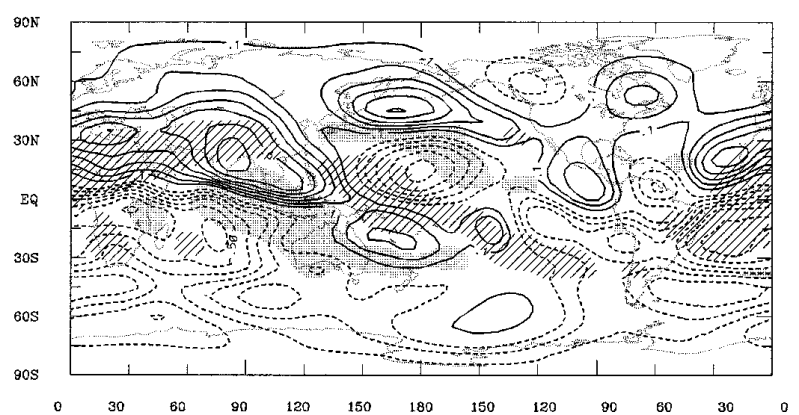

OLR will be described as active (inactive) convection, and positive (negative) correlation coefficients for the streamfunction will be described as clockwise (anticlockwise) circulation.

\section{(e) day 5}

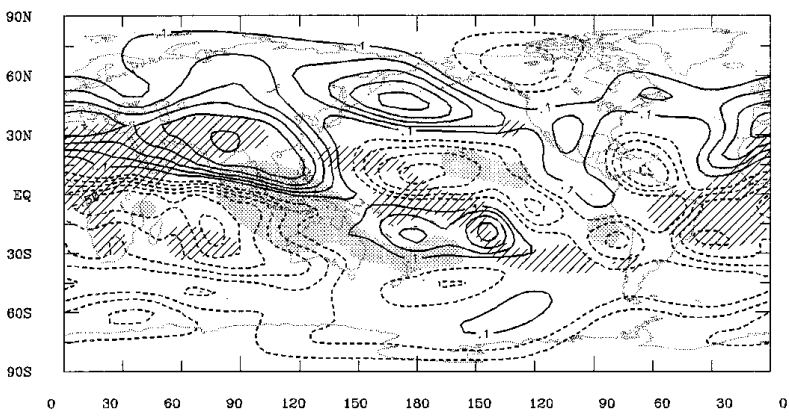

(f) day 10

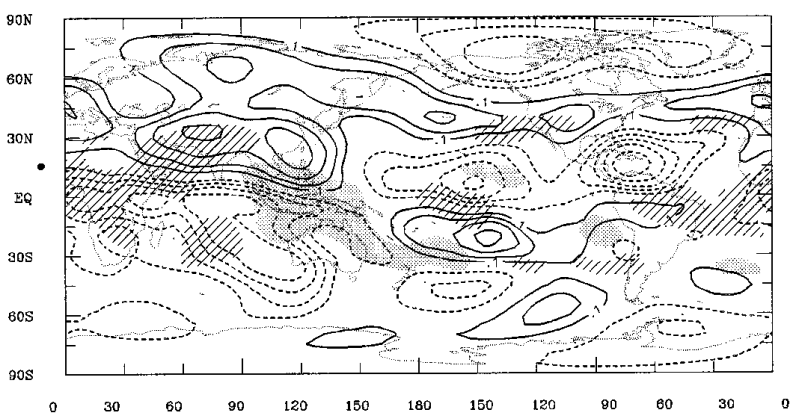

(g) day 15

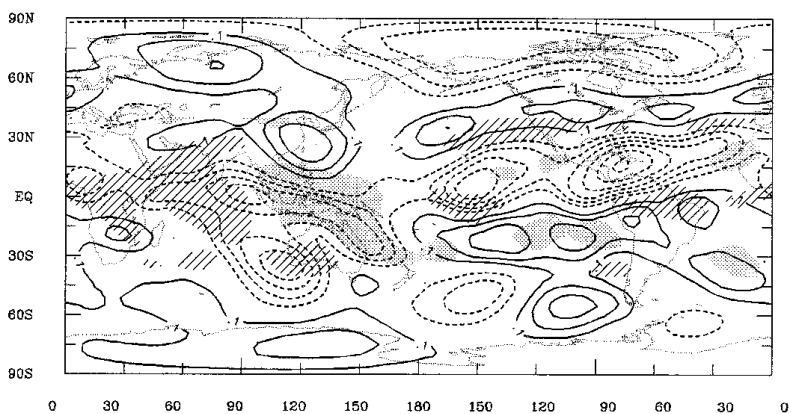

FIG. 2. Correlation maps showing relationship between expansion coefficients of the first OLR vector and the 200-hPa streamfunction field at various time lags: (a) day -15 , (b) day -10 , (c) day -5 , (d) day 0 , (e) day 5 , (f) day 10, (g) day 15 . The contour interval is 0.1 ; solid and dashed lines represent the positive and negative values, respectively. The zero value contour is not drawn. The corresponding OLR patterns are also shown in the shading scheme. Stippling indicates the areas where correlation coefficients are less than -0.2 , and hatching indicates the areas where correlation coefficients are greater than 0.2 .

\section{a. $O L R$}

The time evolution of the first OLR vector from day -15 to day 15 is shown in Fig. 2 in a shading scheme- 
that is, the hatched areas indicating where the correlation coefficients are greater than 0.2 and the stippled areas indicating where the correlation coefficients are less than -0.2 . The absolute values of the maximum correlation in the large shaded regions are generally larger than 0.4. The largest correlation coefficient that occurs in the western Pacific at day 0 exceeds 0.8.

The sequence begins with an OLR pattern similar to the second OLR singular vector, with inactive convection in the maritime continent and active convection in the western Indian Ocean. The pair moves slowly eastward while the convection in the Indian Ocean strengthens reaching its largest amplitude $(-0.82)$ at day 0 (Fig. 2d). At the same time, the region of inactive convection moves to the western Pacific extending southeastward into the South Pacific convergence zone (SPCZ). The OLR anomaly in the Atlantic that was negative at day -15 now becomes positive, indicating weakening convection.

From day 0 to day 15 , the strong convection region continues to move from $115^{\circ}$ to $150^{\circ} \mathrm{E}$. During the same period, the inactive convection region in the western Pacific decays abruptly between day 0 and day 5 , while a new center appears between the date line and $150^{\circ} \mathrm{W}$. A new region of inactive convection also appears in the Indian Ocean and moves eastward. The time evolution indicates little evidence of eastward propagation beyond the date line. The convective activity in Central and South America and the Atlantic is not an eastward extension of the convective activity in the Pacific. Instead, it seems to develop in situ. The time evolution shown above resembles that shown in Knutson and Weickmann (1987).

\section{b. Streamfunction}

The time evolution of the first 200-hPa streamfunction vector is shown in Fig. 2. The anomalous circulation pattern at day -20 (not shown) resembles the pattern at day 5 (Fig. 2e) but the signs are reversed. The circulation pattern over Asia and the northern $\mathrm{Pa}-$ cific disintegrates rapidly from day -20 to day -15 , while the circulation pattern in the Western Hemisphere remains at its peak phase. At the same time, a weak wavelike structure emanating from Indochina appears in the northern Pacific, while the convection to its southern end, that is, in the South China Sea and Indochina, is less active. The wavelike structure develops into a dipole straddling the exit region of the Pacific jet by day -5 . The development is rather dramatic between day -10 and day -5 . A dipole straddling the equator between $30^{\circ}$ and $150^{\circ} \mathrm{E}$ also develops during the same period. By day 0 , a pattern similar to the first vector is fully developed. The structure resembles the global pattern shown in Hsu and Lin (1992) that was derived from one-point correlation statistics. The evolution of the pattern indicates a weakening of the jet stream in the Pacific, equatorial easterly anom- alies from $40^{\circ} \mathrm{W}$ eastward to $135^{\circ} \mathrm{E}$, and equatorial westerly anomalies from $150^{\circ} \mathrm{E}$ to $150^{\circ} \mathrm{W}$. The global pattern develops in situ and there is little evidence to suggest an eastward propagation of the circulation from the Indian Ocean into the western Pacific. The abrupt development of the extratropical dipole in the northern Pacific is a noteworthy feature that will be discussed further in the following sections. The same abrupt development can be seen in the composite of Knutson and Weickmann (1987) but was barely discussed.

At day 0, the dipole of the convection anomalies in the western Pacific and the Indian Ocean is well developed and is located equatorward of the cyclonic and anticyclonic couplets; that is, the cyclonic couplet lay poleward of the inactive convection region and the anticyclonic couplet lay poleward of the active convection region. The phase relationship between the tropical convection activity and the subtropical circulation is, to some extent, consistent with the simulated atmospheric responses to tropical heating (Gill 1980; Simmons et al. 1983; Ting and Sardeshmukh 1993). On the other hand, the convection in the western Pacific has been inactive since day -20 while the anomalous circulation patterns in the northern extratropical Pacific do not develop until day -5 . It raises a doubt whether the existence of extratropical circulation can be attributed solely to tropical forcing. This will be discussed further in the following sections.

A similar phase relationship does not hold in the Atlantic. For example, an inactive convection region is flanked by an anticyclonic couplet to the north and south at day 0 . It is worth noting that these inactive convection regions can be traced back to day -10 when they were located off the equator and equatorward of the anticyclonic anomalies. The phase relationship indicates that the convection variations in the Atlantic region do not act as forcing to the off-the-equatorial circulation anomalies in the subtropics. Park and Schubert (1993) found that the convection may be forced by an extratropical wavelike structure emanating from the Pacific. However, a similar pattern was not evident in Fig. 2. Reason for the discrepancy between two studies is not clear.

From day 0 to day 15, the circulation anomalies in the Eastern Hemisphere weaken while the active convection region moves into the western Pacific and starts to decay. The cyclonic couplet straddling the equator in the central Pacific and the accompanying inactive convection region in the equator drift slowly eastward. Both the circulation and convection anomalies weaken before reaching Central America. During this period, a cyclonic circulation to the east of the Caribbean Sea develops abruptly from day 0 to day 10 . The circulation anomaly in the Western Hemisphere exhibits a more zonal structure and a meridionally banded structure. However, the extratropical circulation anomalies are weaker than their counterparts in the low latitudes. A wavelike pattern similar to that at day -10 , but with 
reversed signs, appears in the northern Pacific by day 20 and develops into a pattern resembling the first singular vector by day 30 (not shown). As a whole, the evolution of the 200-hPa streamfunction pattern in the Northern Hemisphere is characterized by the in situ developments of new centers, that appear successively downstream, while its counterpart in the Southern Hemisphere exhibits a stronger component of eastward propagation.

The time evolution of the $850-\mathrm{hPa}$ streamfunction pattern along with the OLR pattern is shown in Fig. 3. At day -20 , an anticyclonic couplet straddling the equator, restricted between $30^{\circ} \mathrm{N}$ and $30^{\circ} \mathrm{S}$, appears in the Indian Ocean and the western Pacific (not shown). The pattern along with an inactive convection region moves eastward into the Pacific at day -15 . By day -10 , the pattern develops into an anticyclonic couplet with much larger zonal and meridional scales. The development of an anticyclonic circulation anomaly in the subtropical Pacific that is associated with the $200-\mathrm{hPa}$ wavelike structure (Fig. 2b) leads to the larger meridional scale. At the same time, a new cyclonic couplet appears poleward of the active convection in the western Indian Ocean. The 200-hPa tropical circulation pattern at the same period exhibits a structure that is in quadrature with the $850-\mathrm{hPa}$ pattern. This suggests that the circulation pattern at this stage does not possess a deep, coherent vertical structure. By day 0, the anticyclonic couplet has crossed the entire Pacific, extending to South America, while a cyclonic couplet covers the Indian Ocean. The tight gradients along the equator suggest strong easterly anomalies in the Pacific and westerly anomalies in the Indian Ocean. The positive correlation maximum in the northern Pacific appears near $\left(60^{\circ} \mathrm{N}, 180^{\circ} \mathrm{E}\right)$ and is in phase with the northern center of the extratropical dipole at $200 \mathrm{hPa}$ (Fig. 2d).

By day 5 , the region of anticyclonic anomaly extends eastward into the Atlantic, so do the equatorial easterly anomalies. The couplet in the Indian Ocean moves eastward into the western Pacific from day 5 to day 20. The meridional scale of the dipole shrinks during the course. The pattern in the eastern Pacific becomes zonally elongated at day 10 , exhibiting an in-phase relationship with the 200-hPa pattern in both the Tropics and the extratropics. The vertical structure of tropical circulation has changed from an out-of-phase relationship in the western Pacific to an in-phase relationship in the eastern Pacific. It will be shown in section 8 that the in-phase vertical structure becomes evident at day 5 when a zonally symmetric circulation pattern starts to propagate northward from the equator. The existence of the zonally symmetric pattern is evident in Figs. $3 \mathrm{f}$ and $3 \mathrm{~g}$.

The time evolution of the 200- and 850-hPa streamfunction patterns exhibit different characteristics. The 200-hPa pattern tends to develop in situ, showing weak eastward propagation, while the time evolution of the $850-\mathrm{hPa}$ pattern clearly shows an eastward propaga- tion, especially in the Tropics of the Southern Hemisphere. The different characteristics of tropical circulation in the upper and lower troposphere and between the Northern and Southern Hemisphere imply that the circulation in the upper and lower troposphere does not always couple in a way similar to the first internal mode.

\section{Kelvin wave signature}

Mechanism based on equatorial Kelvin wave has been proposed by many researchers as an explanation for the eastward movement of intraseasonal oscillation. It would be interesting to see whether a structure similar to the one in a Kelvin wave can be found in our calculation. One way to judge the existence of a Kelvin wave is to compare the spatial structure of the streamfunction with that of the geopotential height and zonal wind. For an idealized Kelvin wave, its geopotential height and zonal wind distributions are symmetric to the equator, for example, the maximum and minimum are located at the equator, while its streamfunction distribution is antisymmetric; that is, the maximum and minimum are located off the equator. The geopotential height and zonal wind are in phase in a dry Kelvin wave, and exhibit a small phase shift in a moist Kelvin wave (Wang 1988; Lau et al. 1988). If such a spatial structure is found in our results, there is a possibility that it could be the reflection of a Kelvin wave in the real atmosphere.

Lag-correlation maps for the eddy geopotential height at both 1000 and $850 \mathrm{hPa}$ were computed. The results of both fields are very similar. Figures $4 a-c$ show the time evolution of the 1000 -hPa eddy geopotential height from day -10 to day 10 every 10th day. Zonal means were removed to reduce the masking effect of a zonally symmetric pattern on the eddy structure. At day -10, positive height anomalies cover the Pacific, while negative height anomalies cover the Indian Ocean and the Eurasian continent. A comparison to the $850-\mathrm{hPa}$ streamfunction shows the following features. The positive height anomaly is associated with an anticyclonic couplet off the equator and an easterly anomaly at the equator, while the negative height anomaly is associated with a cyclonic couplet off the equator and a westerly anomaly at the equator. The phase relationship between the height, wind, and streamfunction fields is inconsistent with the structure of equatorial Kelvin waves (e.g., Matsuno 1966; Hendon 1986).

By day 0, the off-the-equator positive correlation maximum in the southern Pacific has moved to the central Pacific while a narrow band of weak negative correlation appears on the equator and extends from the negative correlation region in the west all the way to Central America. A closer examination of the time evolution between day -10 and day 0 indicates that the weak negative correlation appears simultaneously 


\section{(a) day -15}

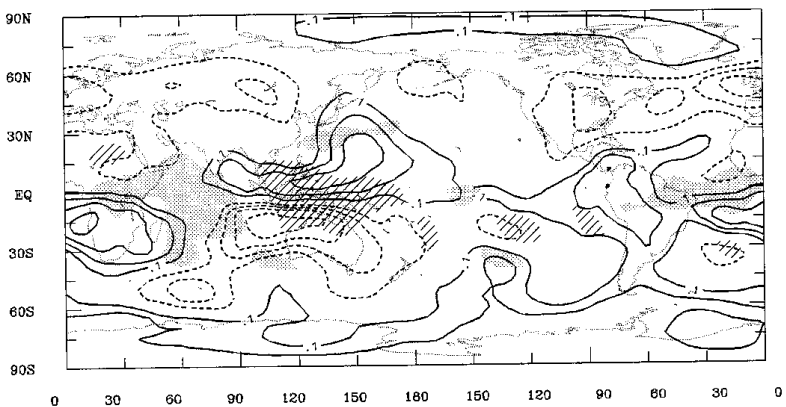

(b) day - 10

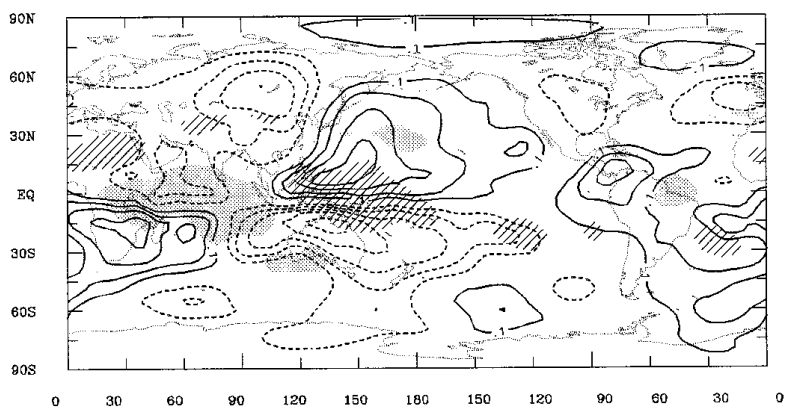

(c) day -5

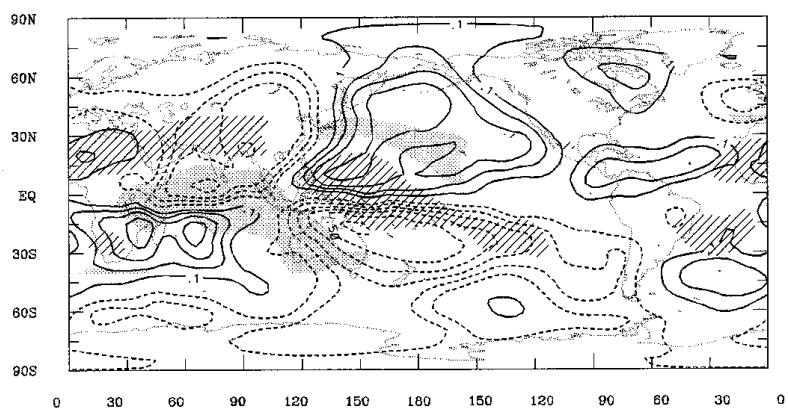

(d) day 0

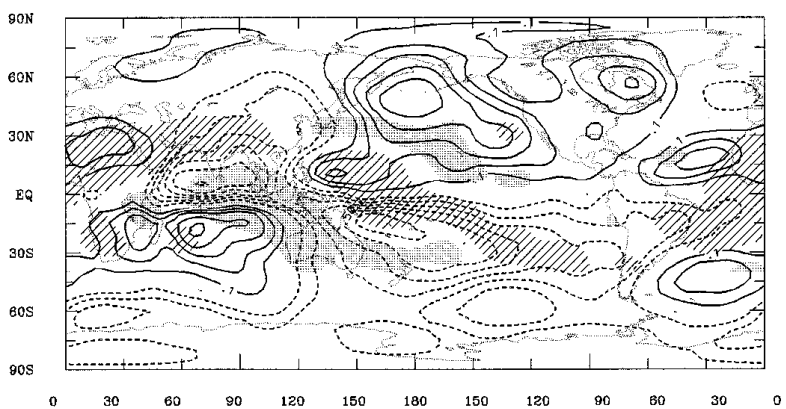

across the Pacific basin and that there is no indication of eastward propagation originating in the western $\mathrm{Pa}$ cific. From day 0 to day 10 , the region of negative correlation in the southern Indian Ocean moves into the

\section{(e) day 5}

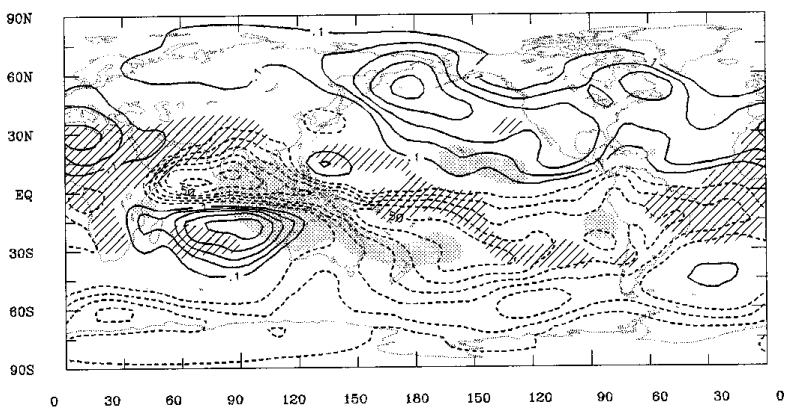

(f) day 10

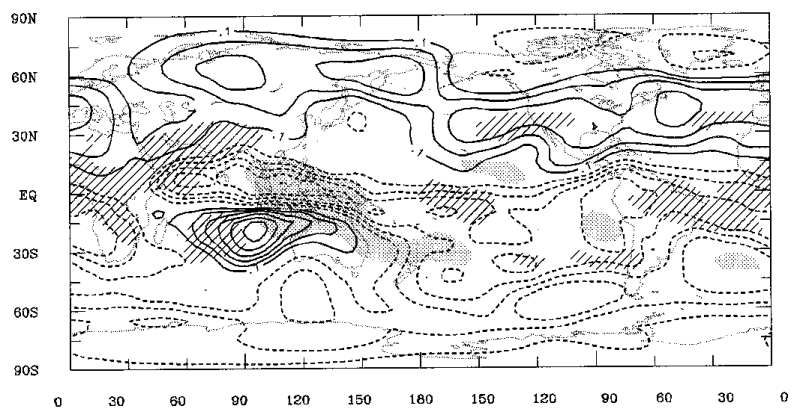

(g) day 15

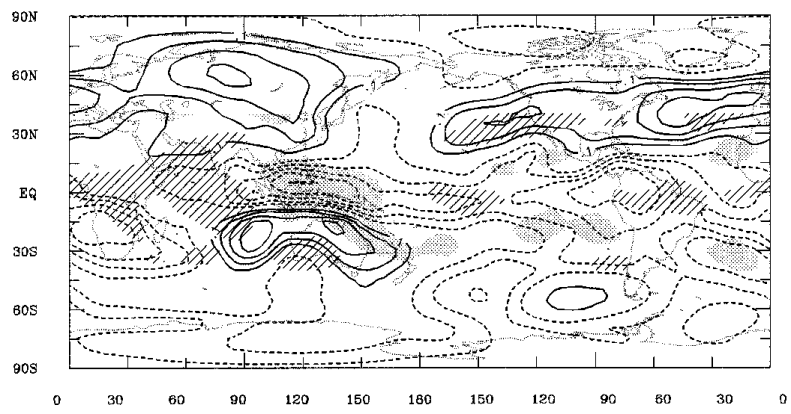

FIG. 3. Same as in Fig. 2 but for the $850-\mathrm{hPa}$ streamfunction field. southern Pacific while the region of negative correlation in the equatorial Pacific strengthens and extends to the eastern Pacific. Overall, the correlation near the equator is weaker than off the equator. The off-the- 
(a) day -10

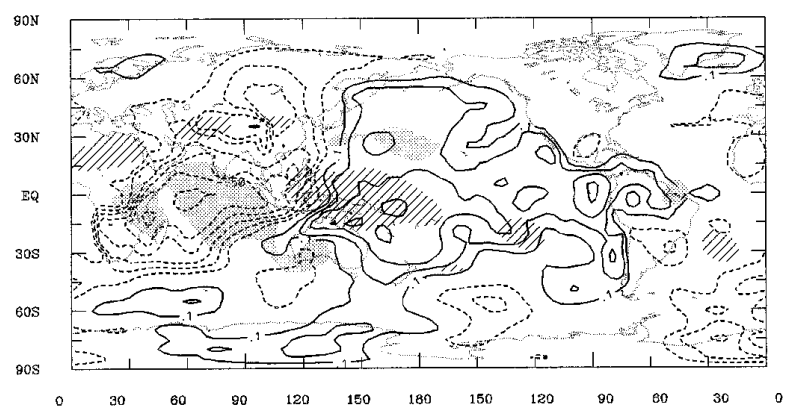

(b) day 0

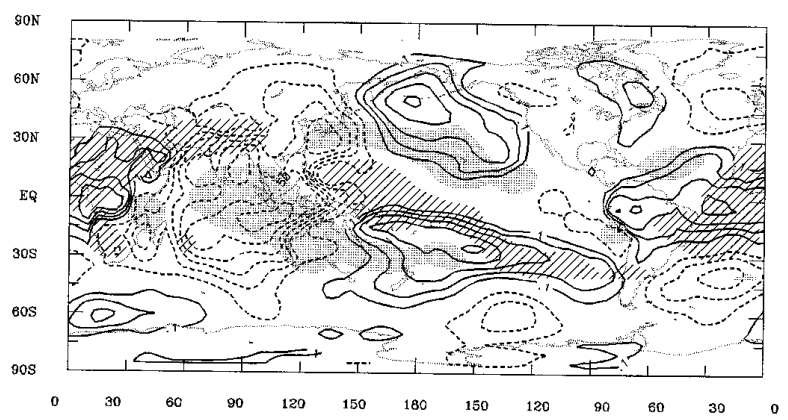

(c) day 10

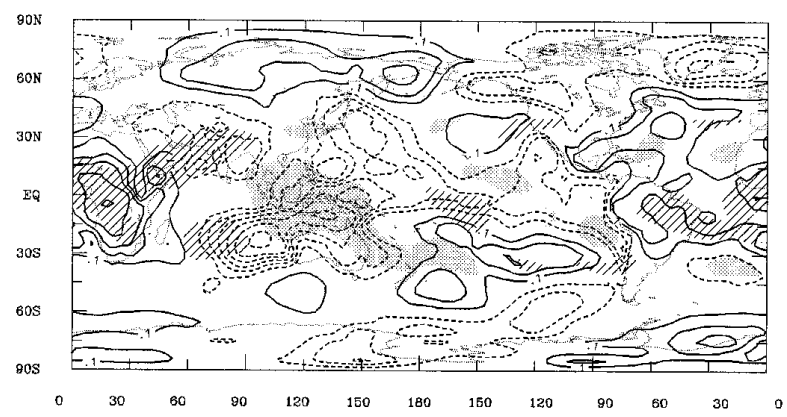

(d) day -10

$200 \mathrm{hPa} \mathrm{H}$

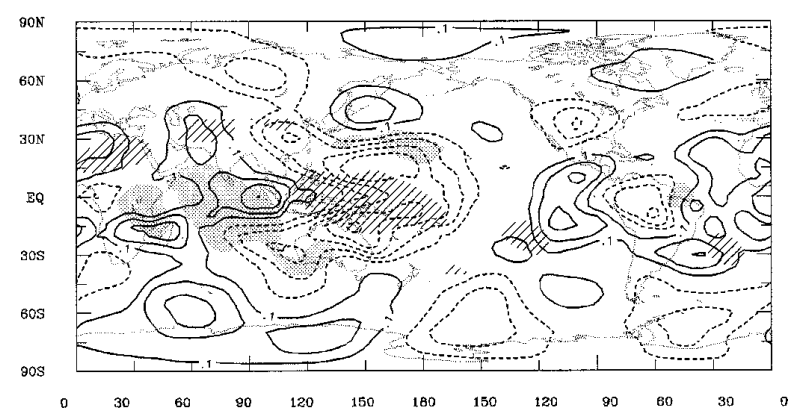

(e) day 0

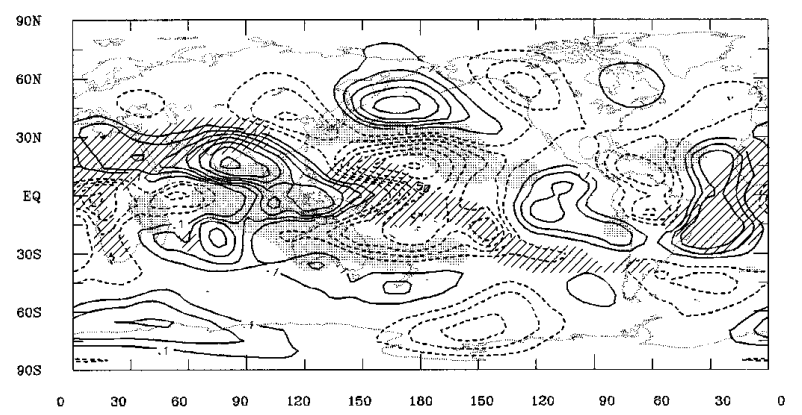

(f) day 10

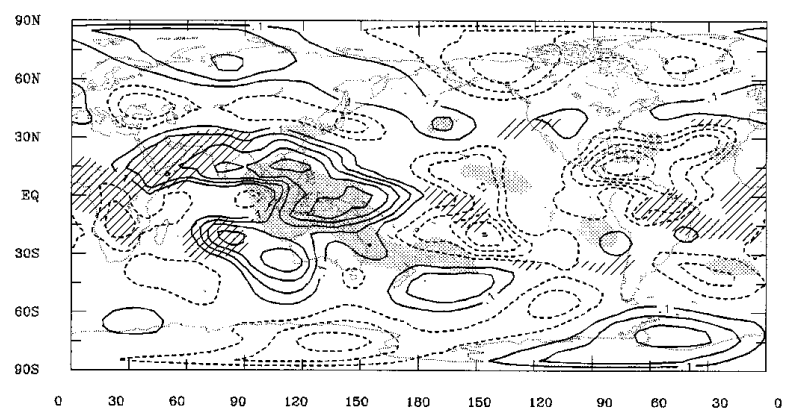

FIG. 4. Correlation maps showing relationships between expansion coefficients of the first OLR vector and the eddy component of the $1000 \mathrm{hPa}$ (left panel) and $200 \mathrm{hPa}$ (right panel) height fields at various time lags: (a, d) day -10 , (b, e) day 0 , (c, f) day 10. The contour interval is 0.1 ; solid and dashed lines represent positive and negative values, respectively. The zero value contour is not drawn. The corresponding eddy OLR patterns are also shown in the same shading scheme as in Fig. 2.

equator maximums are located to the poleward side of the tropical convection fluctuations and tend to be inphase with the streamfunction couplets. The phase relationship between the streamfunction and the height fields suggests the characteristics similar to Rossby waves.

Similar correlation statistics were also computed for the eddy geopotential height at $200 \mathrm{hPa}$. The maps from day -10 to day 10 are shown in Figs. $4 d-f$. Most of maximum and minimum correlation is evidently located off the equator and tends to be in phase with the 200-hPa streamfunction pattern shown in Fig. 2. There is a local maximum at the equator in the Eastern Hemisphere in Figs. 4e, f, for example, the negative corre- lation region over the equatorial Indian Ocean and the positive correlation region over the maritime continent. The wedgelike positive correlation region over the maritime continent is associated with the off-the-equator anticyclonic circulations, equatorial easterly anomalies, and active convection to the west at day 0 . The phase relationship again is not consistent with the structure of an equatorial Kelvin wave. The off-the-equator positive correlation regions over South Asia and the southern Indian Ocean coincide with the anticyclonic couplet in Fig. 2d.

Hovmöller diagrams of the lag-correlation coefficients for the eddy geopotential height and zonal wind fields, averaged between $5^{\circ} \mathrm{N}$ and $5^{\circ} \mathrm{S}$, at 200 and 850 
$\mathrm{hPa}$ are shown in Figs. 5a and 5b, respectively, to summarize the phase relationship between the wind and height fields. At $200 \mathrm{hPa}$, the zonal wind and the height fields are out of phase in the central Pacific, in quadrature in the western Pacific, and in phase from $0^{\circ}$ to $70^{\circ} \mathrm{E}$. The phase relationship in the central and western Pacific is inconsistent with the characteristics of equatorial Kelvin waves. In the region from $0^{\circ}$ to $70^{\circ} \mathrm{E}$, the phase relationship is consistent with the characteristic of a Kelvin wave. The convective activity in the region, however, is weak. At $850 \mathrm{hPa}$, westerly (easterly) anomalies lag behind negative (positive) height anomalies by about a quarter of the cycle. The phase relationship again does not support the existence of equatorial Kelvin waves in the eastern Indian Ocean and western Pacific where the convection is most active.

\section{Standing oscillation versus zonal propagation}

In this section, we examine the relative importance of zonally propagating features and standing oscillations. The Hovmöller diagrams shown in Fig. 6 present the lag correlation coefficients between the expansion coefficient and the OLR, divergence and velocity potential fields, averaged between $5^{\circ} \mathrm{N}$ and $5^{\circ} \mathrm{S}$, to show the time evolution of the respective field. The zonal means were subtracted to show zonal propagation more clearly. The lag correlation coefficients for OLR shown in Fig. 6a indicate an eastward propagation of convective activity from $60^{\circ} \mathrm{E}$ to the date line and a period of about 50 days. There is no evidence of eastward propagation beyond the date line. A closer examination also indicates the tendency of tropical convection to amplify at certain longitudes. The recurrence of the positive and negative correlation centers at the same longitudes suggests the existence of standing oscillations, besides the eastward propagation. Standing oscillations are most noticeable near $45^{\circ} \mathrm{E}, 90^{\circ}-120^{\circ} \mathrm{E}, 150^{\circ} \mathrm{E}-180^{\circ}$, and $30^{\circ} \mathrm{W}-0^{\circ}$.

The time evolution of the 200-hPa divergence shown in Fig. $6 \mathrm{~b}$ resembles the time evolution of the OLR, especially in the Indian Ocean, the western Pacific, and the Atlantic. Signals of standing oscillations are even more evident. While both the OLR and the $200-\mathrm{hPa}$ divergence show eastward propagation from the Indian Ocean to the date line, the time evolution of $850-\mathrm{hPa}$ divergence in Fig. 6c indicates that the eastward propagation occurs only between $110^{\circ}$ and $150^{\circ} \mathrm{E}$. Standing oscillations in the Indian Ocean and in the western Pacific characterize the time evolution. On the whole, the OLR and $200 \mathrm{hPa}$ exhibit a pattern whose evolution is different from the one at $850 \mathrm{hPa}$. The tropical circulation in the area seems to bear a vertical structure more complicated than the first internal mode in the tropical troposphere.

The time evolution of the velocity potential has been widely examined, to infer the eastward propagation of the tropical convection, and has been interpreted as an (a) $200 \mathrm{hPa} \mathrm{H} \& \mathrm{U}$

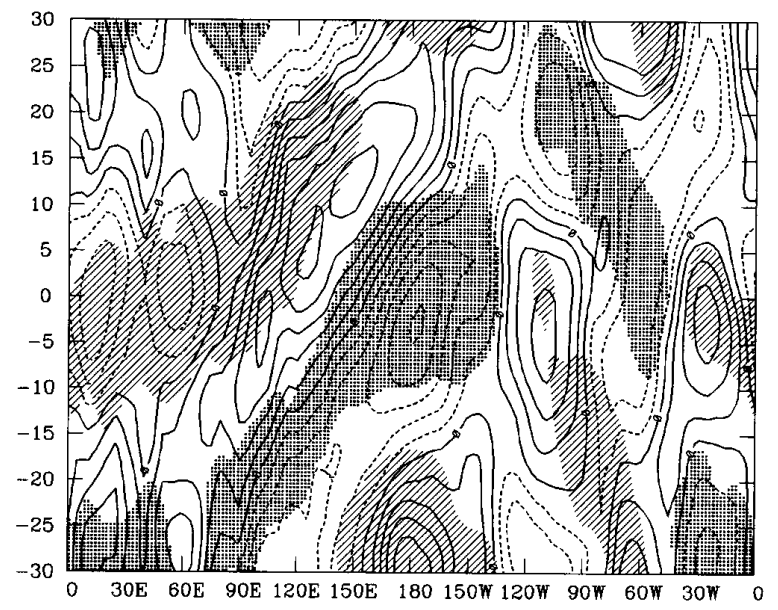

(b) 850 hPa H \& U

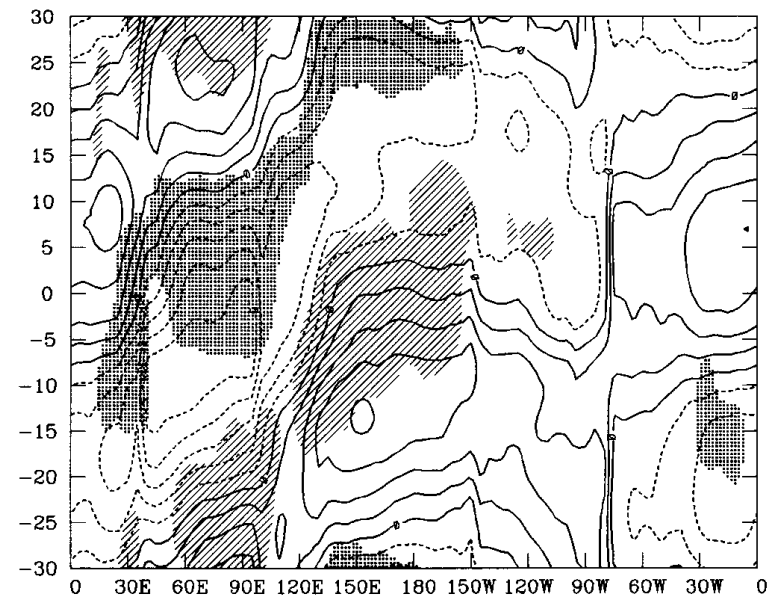

FIG. 5. Hovmöller diagrams of the correlation coefficients between the expansion coefficient of the first OLR vector and the eddy component of (a) the 200-hPa height and (b) the $850-\mathrm{hPa}$ height fields averaged between $5^{\circ} \mathrm{N}$ and $5^{\circ} \mathrm{S}$ from day -30 to day 30. Lag-correlation coefficients for the zonal wind at 200 and $850 \mathrm{hPa}$ are indicated by shading scheme. Stippling and hatching indicate where the correlation coefficients are greater than 0.2 and less than -0.2 , respectively. Contour interval is 0.1 .

equatorial Kelvin wave. The Hovmöller diagram of the 200-hPa velocity potential shown in Fig. 6d, like those shown in many previous studies, shows an eastward propagation of the signals around the globe. The impression one may have from the time evolution of the velocity potential is rather different from the time evolution of the OLR and the divergence fields shown above. The slope of the maximum correlation region in Fig. 6d also yields a faster speed than that may be deduced based on Figs. 6a-c. The misrepresentation of the velocity potential is obvious and its interpretation should be made with caution. 
(a) OLR *

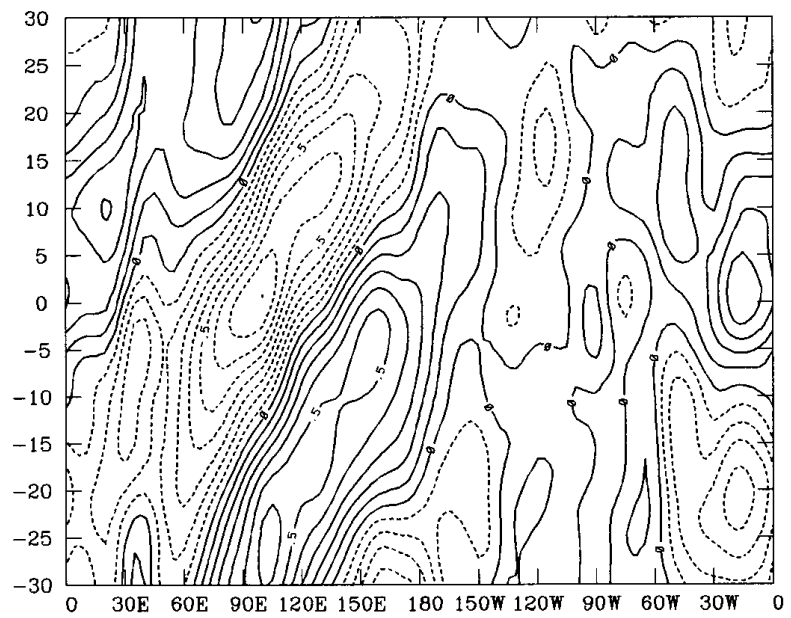

(b) $200 \mathrm{hPa}(\nabla \cdot \mathrm{V})^{*} \& \mathrm{OLR}^{*}$

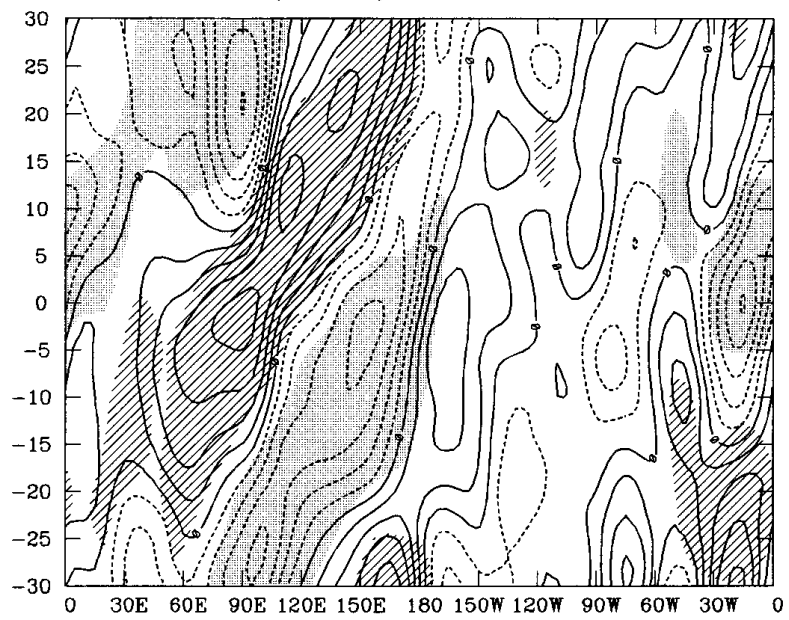

(c) $850 \mathrm{hPa} \& 200 \mathrm{hPa}(\nabla \cdot \mathrm{V})$ *

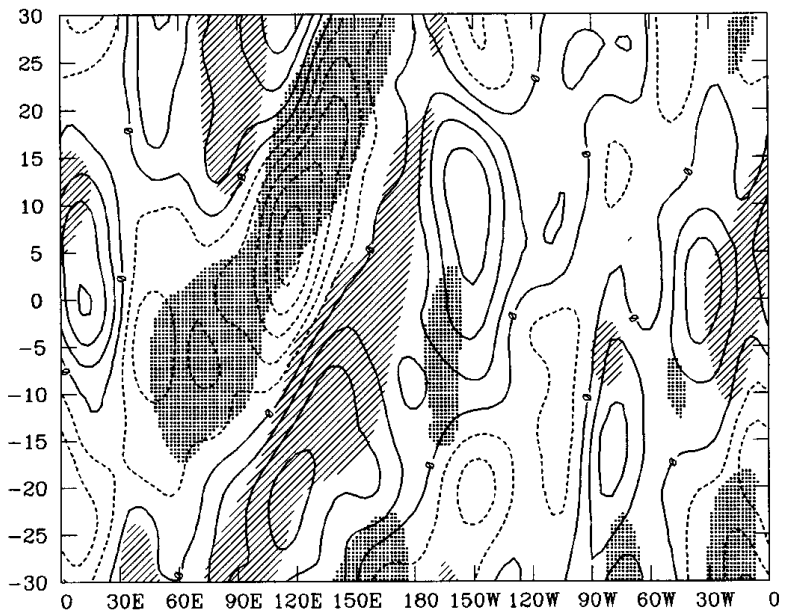

(d) $200 \mathrm{hPa} \chi^{\star} \&$ OLR*

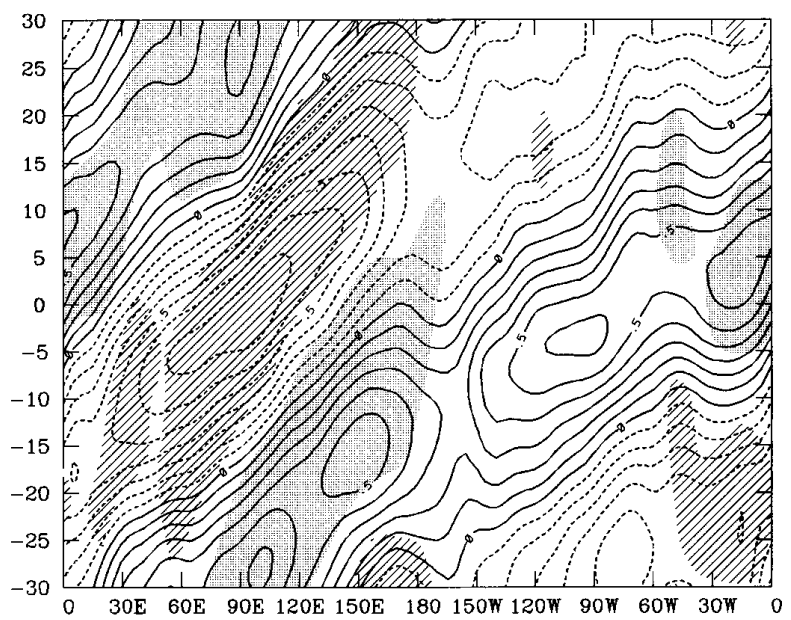

FIG. 6. Hovmöller diagrams of correlation coefficients between the expansion coefficient of the first OLR vector and the eddy component of (a) OLR; (b) 200-hPa divergence (contoured) and OLR (shaded); (c) 850-hPa (contoured) and 200-hPa divergence (shaded); and (d) 200$\mathrm{hPa}$ velocity potential (contoured) and OLR (shaded), averaged from $5^{\circ} \mathrm{N}$ to $5^{\circ} \mathrm{S}$ and from day -30 to day 30 . Stippling and hatching indicate where the correlation coefficients are greater than 0.2 and less than -0.2 , respectively. Contour interval is 0.1 .

Standing oscillation signals are also evident in other fields. Shaded regions in Fig. 7 indicate the fluctuation of the eddy component of the zonal wind averaged between $5^{\circ} \mathrm{N}$ and $5^{\circ} \mathrm{S}$. Its fluctuations tend to be in phase with the 200-hPa streamfunction averaged in the $10^{\circ}-$ $20^{\circ} \mathrm{N}$ (Fig. 7a) and $10^{\circ}-20^{\circ} \mathrm{S}$ (Fig. 7b) latitudinal bands. The in-phase relationship suggests the dominance of rotational wind. Standing oscillations, especially evident in the Northern Hemisphere, seem to occur at all longitudes but are more evident near $20^{\circ} \mathrm{E}$, $100^{\circ} \mathrm{E}, 180^{\circ}, 90^{\circ} \mathrm{W}$, and $15^{\circ} \mathrm{W}$. Propagating features are also noticeable. The eastward propagation that is most evident in the Southern Hemisphere occurs only in the longitudinal domain where the OLR and divergence patterns also propagate eastward. Around-the-globe propagation is again not evident in the Northern Hemisphere but is more evident in the Southern Hemisphere, although the signals are very weak in the Western Hemisphere. Besides the eastward propagation, a westward propagation between $120^{\circ}$ and $60^{\circ} \mathrm{W}$ in the Northern Hemisphere is evident both in the equatorial zonal wind and streamfunction (Fig. 7a).

At $850 \mathrm{hPa}$, the zonal wind averaged between $5^{\circ} \mathrm{N}$ and $5^{\circ} \mathrm{S}$ (shaded areas in Fig. 7c) and the streamfunction averaged between $10^{\circ}$ and $20^{\circ} \mathrm{N}$ (Fig. 7c) also exhibit strong signals of standing oscillation that occurs mainly in the Indian Ocean and the western Pacific. However, the streamfunction averaged between $10^{\circ}$ and $20^{\circ} \mathrm{S}$ (Fig. 7d) clearly exhibits an eastward propagation. The contrast between the time evolution of the 
(a) $200 \mathrm{hPa} \psi^{*}\left(10^{\circ} \mathrm{N} \sim 20^{\circ} \mathrm{N}\right)$

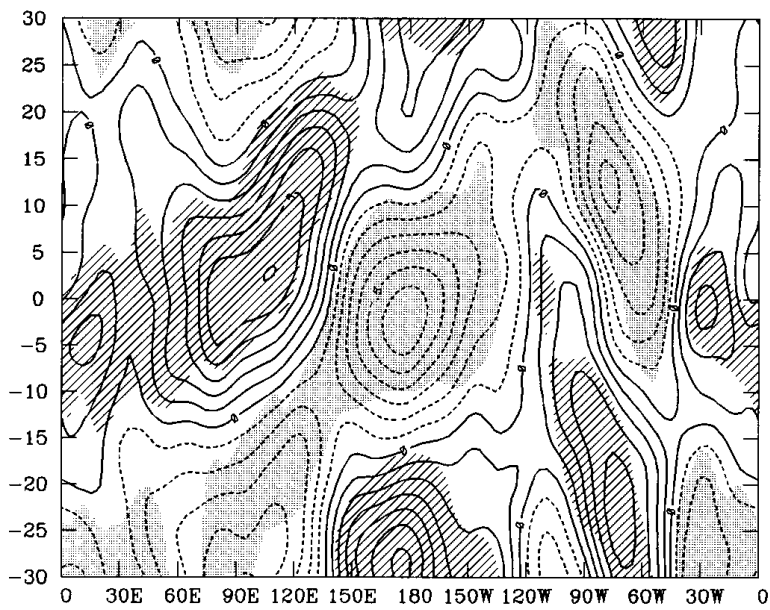

(b) $200 \mathrm{hPa} \psi^{*}\left(10^{\circ} \mathrm{S} \sim 20^{\circ} \mathrm{S}\right)$

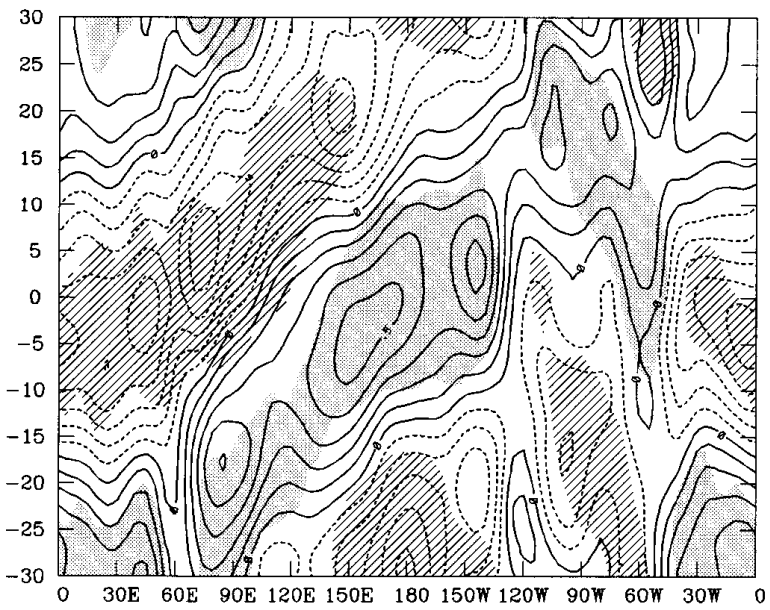

(c) $850 \mathrm{hPa} \psi^{*}\left(10^{\circ} \mathrm{N} \sim 20^{\circ} \mathrm{N}\right)$

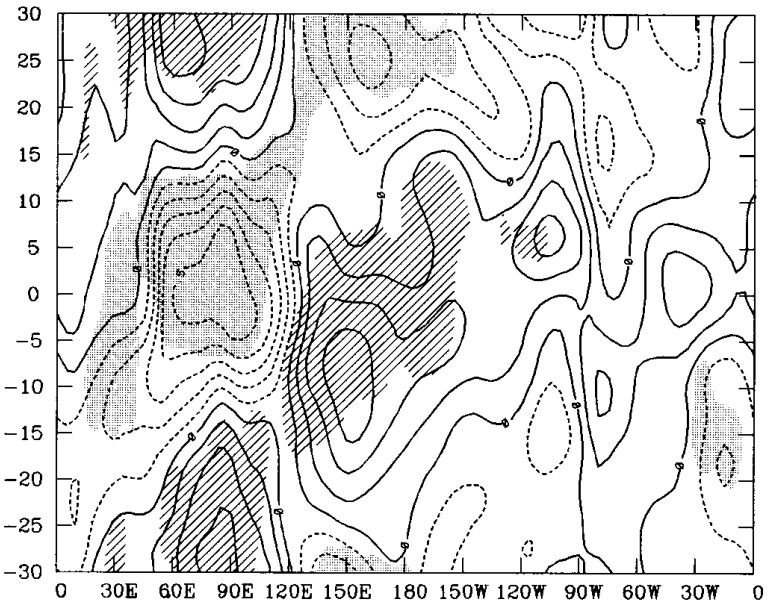

(d) $850 \mathrm{hPa} \psi^{*}\left(10^{\circ} \mathrm{S} \sim 20^{\circ} \mathrm{S}\right)$

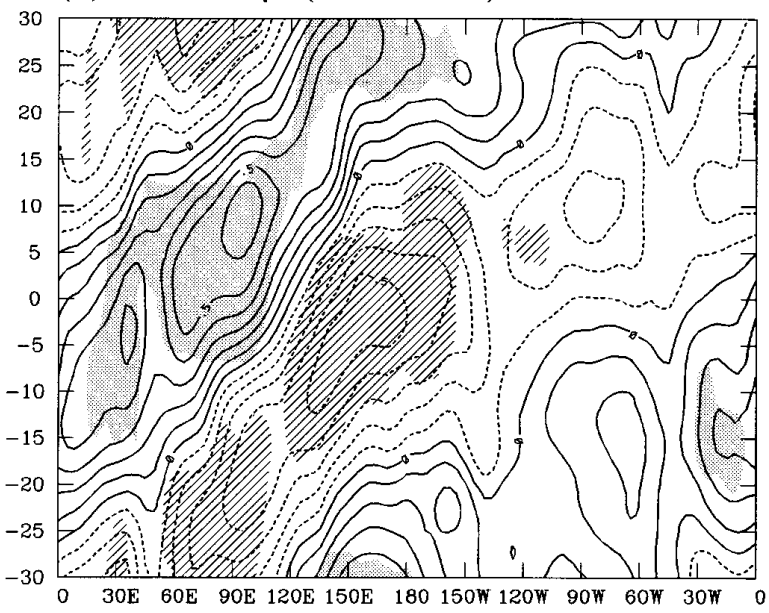

FIG. 7. Hovmöller diagrams of the correlation coefficients between the expansion coefficient of the first OLR vector and the eddy component of (a) the $200-\mathrm{hPa}$ streamfunction averaged between $10^{\circ}$ and $20^{\circ} \mathrm{N}$, and (b) the $200-\mathrm{hPa}$ streamfunction averaged between $10^{\circ}$ and $20^{\circ} \mathrm{S}$, from day -30 to day 30 . Stippling and hatching indicate where the correlation coefficients for the $200-\mathrm{hPa}$ zonal wind, averaged between $5^{\circ} \mathrm{N}$ and $5^{\circ} \mathrm{S}$ are greater than 0.2 and less than -0.2 . (c) and (d) are the same as (a) and (b) but for $850 \mathrm{hPa}$. Contour interval is 0.1 .

streamfunction fields in the Northern and Southern Hemisphere is also evident in Fig. 3.

\section{Rossby wave source}

As pointed out by Sardeshmukh and Hoskins (1988), the atmospheric response to the tropical divergence is determined by the distribution of Rossby wave source (hereafter, referred to as RWS) that depends on the relative position of the divergence and the absolute vorticity fields. In this section, we examine the evolution of the RWS to yield useful information to explain the contrasting time evolution between the circulation in the Northern and Southern Hemispheresthat is, the relative importance of standing oscillation and propagation. Linearized vorticity equation can be written as follows:

$$
\begin{aligned}
\frac{\partial \zeta^{\prime}}{\partial \mathbf{t}}=-\overline{\mathbf{V}_{\psi}} \cdot \nabla \zeta^{\prime}- & \mathbf{V}_{\psi}^{\prime} \cdot \nabla \bar{\zeta} \\
& -\nabla \cdot\left(\mathbf{V}_{\chi}^{\prime} \bar{\zeta}\right)-\nabla \cdot\left(\overline{\mathbf{V}_{\chi}} \zeta^{\prime}\right),
\end{aligned}
$$

where $\mathbf{V}_{\psi}$ and $\mathbf{V}_{\chi}$ are rotational and divergent winds, respectively, and $\zeta$ represents the absolute vorticity. The prime and overbar denote the perturbation and climatological mean, respectively. Sum of the third and fourth terms is defined as RWS.

To compute the RWS, we first calculated the lag regression coefficients of the wind fields on the expansion coefficient, that was then multiplied by one standard deviation of the expansion coefficient. By doing that, we reconstructed the wind anomalies when the variation of the expansion coefficient is equal to one standard deviation. The anomalies can be seen as the 
composite weighted by the expansion coefficients shown in Fig. 1. The approach adopted has been used in many studies, for example, Wright et al. (1988), Kiladis and Weickmann (1992), Hendon and Salby (1994). The reconstructed wind fields (not shown here) were used to compute RWS. An examination on RWS will provide information about the effect of the divergence flow when the circulation pattern shown above prevails in the atmosphere.

The distribution of the RWS from day -15 to day 15 every 10th day is shown in Fig. 8. A region of negative RWS over Japan appears to be stationary from day -15 to day 5 . It is replaced by a region of positive RWS at day 15 while the region of negative RWS shifts to the date line. The evolution occurs concurrently with the evolution of the divergence field at $200 \mathrm{hPa}$. A north-south dipole over East Asia exists between day -15 and day 5 as shown in Fig. 9. The divergence center over Japan, located near the Pacific subtropical jet core where relative vorticity is the largest, contributes to the RWS minimum. As the tropical convection in the western Pacific switches from its inactive phases to its active phase between day -10 and day 10, the Rossby wave source over Japan also switches from negative sign to positive sign when the divergence is replaced by convergence.

Sardeshmukh and Hoskins (1988) noted the importance of the vorticity advection by divergent winds associated with prescribed tropical divergence, which was also confirmed by Hsu (1994). The RWS shown above, however, indicates weak forcing in the Tropics and exhibits close correspondence with the local divergence and convergence in the extratropics. It follows that the forcing is largely contributed by the divergence effect and not by the advection of divergent winds. To demonstrate this, the two terms comprising RWS in Eq. (1) were computed. The fourth term is negligible compared to the third term. The flux term associated with eddy divergent flow can be further decomposed into two terms, that is, the divergence term and the advection term, as follows:

$$
-\nabla \cdot\left(\mathbf{V}_{\chi}^{\prime} \bar{\zeta}\right)=-\bar{\zeta} \nabla \cdot \mathbf{V}_{\chi}^{\prime}-\mathbf{V}_{\chi}^{\prime} \cdot \nabla \bar{\zeta}
$$

Figures 10a,b shows the contribution of the first and second terms in the right-hand side of Eq. (2) at day -5 . The dominance of the divergence term over the advection term is evident. The contribution of the advection term by divergent winds occurs mainly in two regions where both the climatological relative vorticity and the divergence anomalies exhibit large gradient. It can be inferred from Fig. 9c that the divergent wind anomalies in the region southwest of Japan are downgradient of mean absolute vorticity, resulting in positive RWS. At the same time, the divergent wind anomalies over northern India and the Arabian Peninsula are upgradient of mean absolute vorticity, resulting in negative RWS. The contribution of the advection term is, however, much smaller than that of the divergence

\section{(a) day -15}

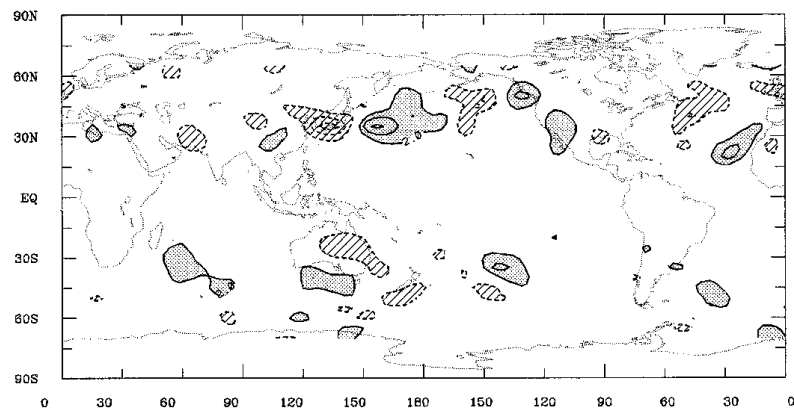

(b) day -5

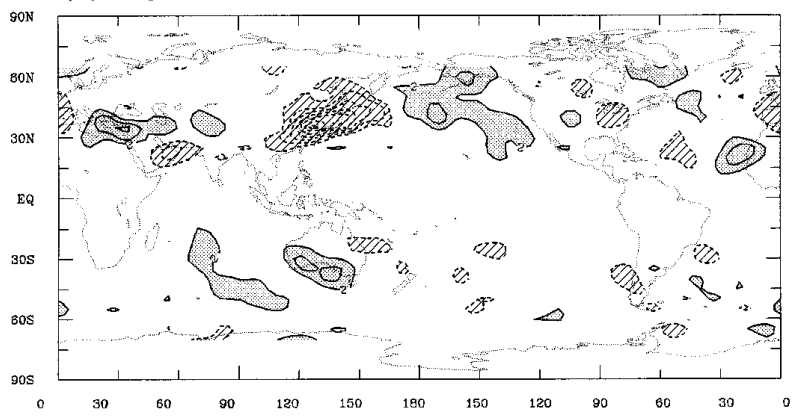

(c) day 5

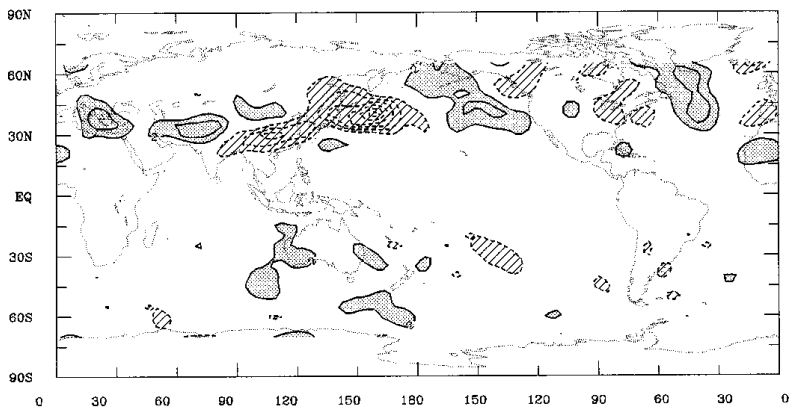

\section{(d) day 15}

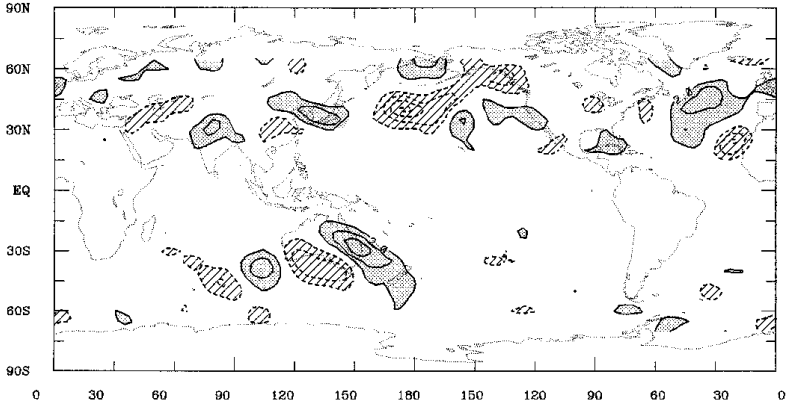

FIG. 8. Rossby wave sources calculated from reconstructed wind anomalies at (a) day -15 , (b) day -5 , (c) day 5 , and (d) day 15 . The contour interval is $2 \times 10^{-11} \mathrm{~s}^{-2}$. Stippling and hatching indicate where the values are greater than $2 \times 10^{-11} \mathrm{~s}^{-2}$ and less than -2 $\times 10^{-11} \mathrm{~s}^{-2}$, respectively. 
(a) day -15

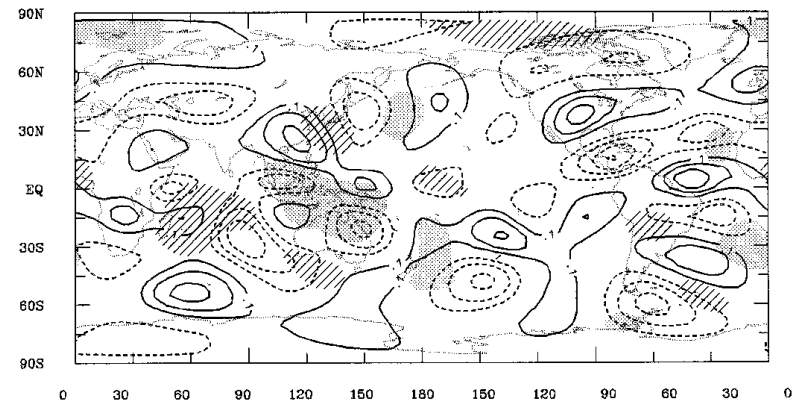

(b) day -10

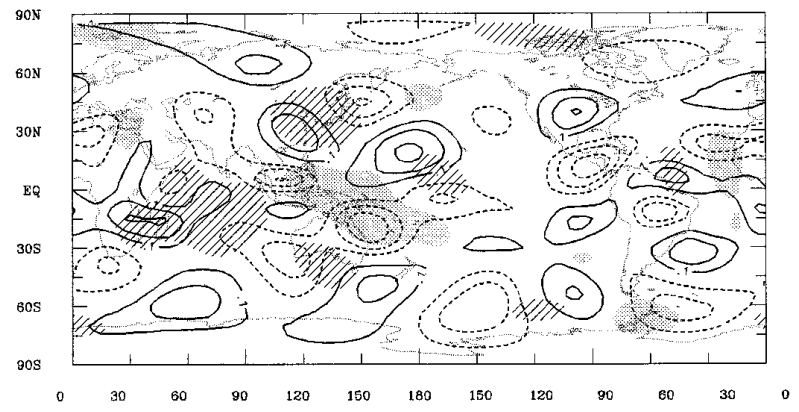

(c) day -5

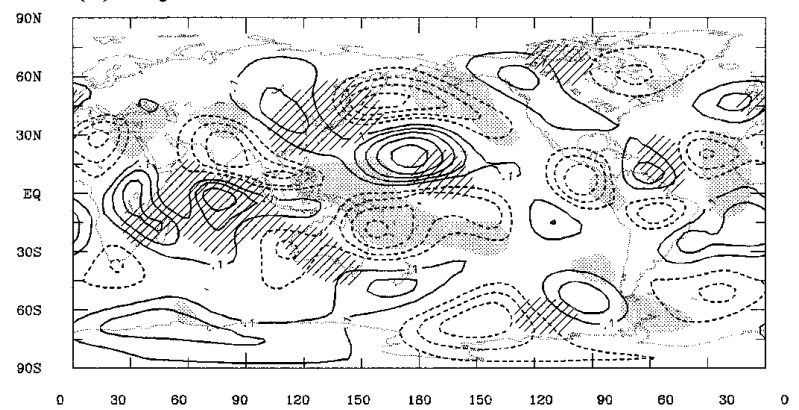

(d) day 0

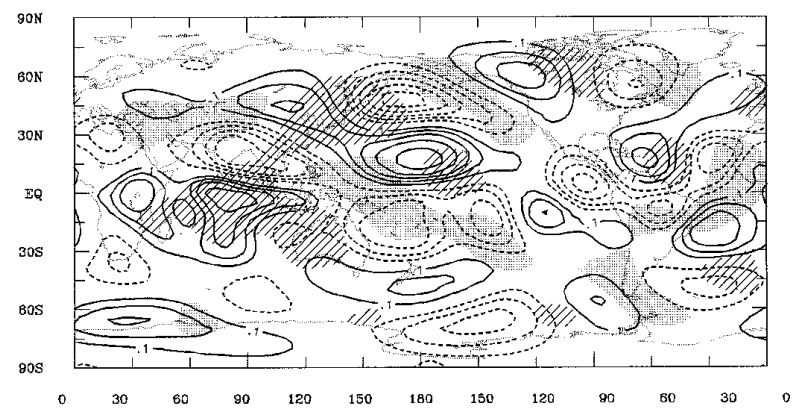

term. This result does not contradict the conclusion of Sardeshmukh and Hoskins (1988), because only tropical divergence was prescribed in their study. In the case of weak extratropical divergence, their conclusions can still be valid.

\section{(e) day 5}

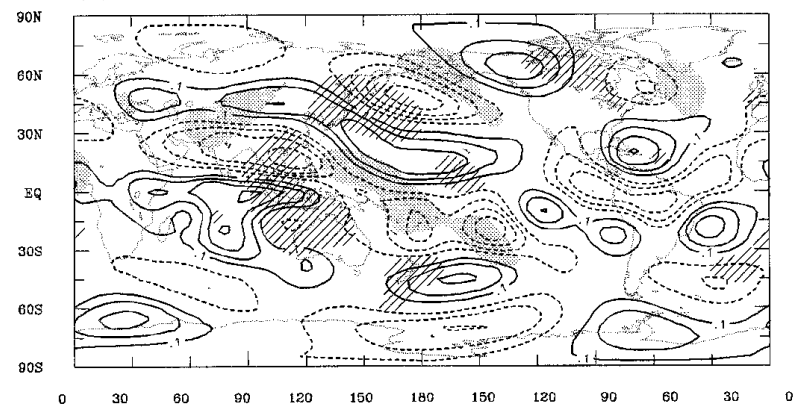

(f) day 10

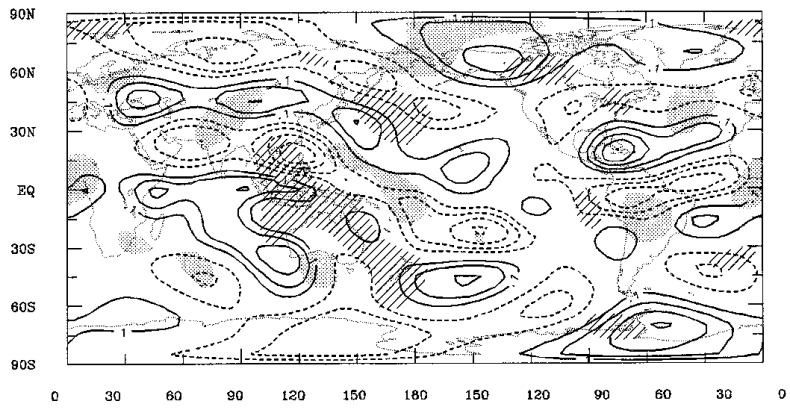

(g) day 15

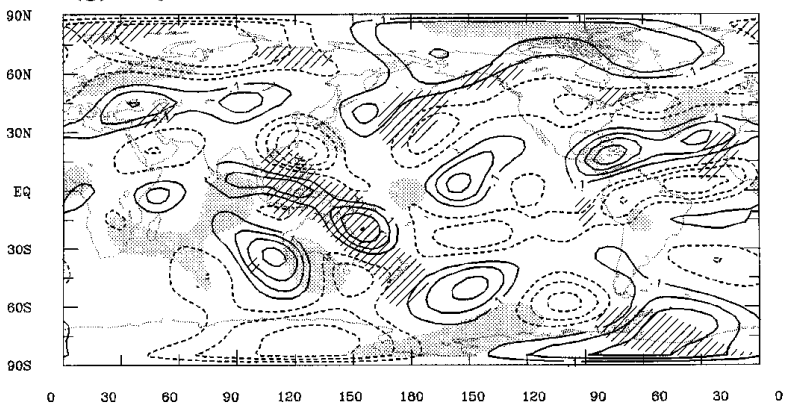

FIG. 9. Correlation maps between the expansion coefficient of the first OLR vector and the 200-hPa vorticity (contoured) and divergence (shaded) fields at various time lags: (a) day -15 , (b) day -10 , (c) day -5 , (d) day 0 , (e) day 5 , (f) day 10 , and $(\mathrm{g})$ day 15 . The contour interval is 0.1 and the zero value contour is not drawn. Stippling and hatching indicate where the divergence correlation coefficients are less than -0.2 and greater than 0.2 , respectively.

The divergence perturbation over Japan develops from a wavelike pattern emanating from the eastern Indian Ocean into the northern Pacific, which can be seen clearly in Fig. 9a. The corresponding divergence pattern is in quadrature with the vorticity pattern in 
(a) $-\bar{\zeta} \nabla \cdot V^{\prime} x$

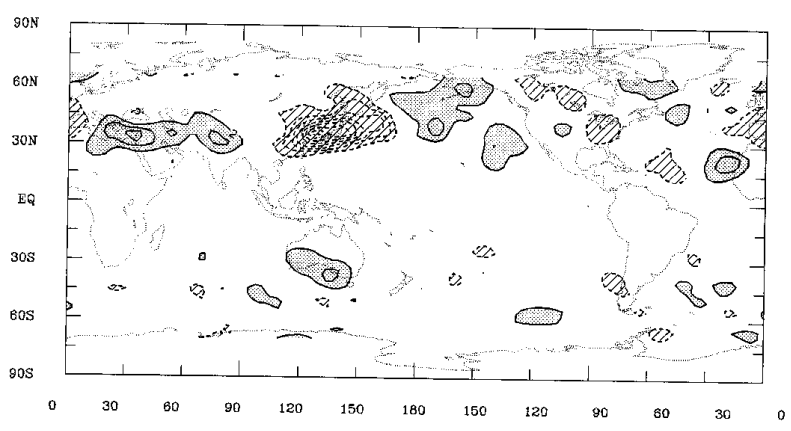

(b) $-V^{\prime}{ }_{z} \bullet \nabla \bar{\zeta}$

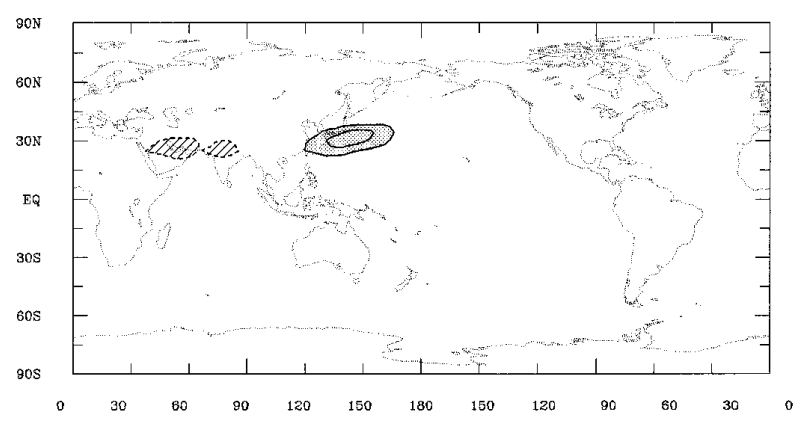

FIG. 10. Plots of (a) $-\bar{\zeta} \nabla \cdot \mathbf{V}_{\chi}^{\prime}$, (b) $-\mathbf{V}_{\chi}^{\prime} \cdot \nabla \bar{\zeta}$ at $200 \mathrm{hPa}$ for day -5 . Contour interval is $2 \times 10^{-11} \mathrm{~s}^{-2}$ and the zero value contour is not plotted. Shading scheme as in Fig. 8.

such a manner that the divergence (convergence) anomalies are located downstream of the positive (negative) vorticity anomalies. The existence of a northsouth dipole of the divergence suggests a modulation of the local Hadley circulation by the intraseasonal oscillation. The divergence anomaly over the east coast of East Asia appears to be quasi-stationary and begins to weaken when the tropical divergence anomaly moves into the western Pacific at day 10. Its stationarity leads to a slow variation in the RWS distribution in the northern Pacific, shown in Fig. 8. Because of the almost stationary divergence maximum in the extratropics, the distribution of the RWS in the northern Pacific is relatively insensitive to the position of tropical convection, and its variation is relatively small when compared to the variation of tropical convection in the western Pacific. The extratropical circulation therefore varies little, appearing to be stationary during the above period and does not change significantly until the complete reversal of tropical convection and the local Hadley cell in the western Pacific.

While extratropical circulations are active in the Northern Hemisphere, circulations in the Southern Hemisphere, particularly in the lower troposphere, are mostly confined to the Tropics. This contrast between the Northern and Southern Hemisphere is also evident in the RWS distribution shown in Fig. 8. In the Northern Hemisphere, the RWS in the extratropics overwhelms the RWS in the Tropics because of the large vorticity and its gradient near the jet streams. In the Southern Hemisphere, the RWS in the extratropics no longer dominates the RWS in the Tropics because of the jet stream that is much weaker. The RWS distribution at $850 \mathrm{hPa}$ also shows similar contrasting behavior.

The above results are consistent with Jin and Hoskins (1995). They used a baroclinic model to examine the effect of basic flow on wave propagation and concluded that the atmospheric responses to the tropical heating are sensitive to the structure of the basic flow. For example, they found that equatorial waves, especially Kelvin waves, only play an important role in the simulations taking a resting atmosphere as the basic state. In a climatological zonally symmetric basic state, the initial perturbation evolves into Rossby wavetrains that prevail mostly in the winter hemisphere. A modal structure similar to the Pacific-North America pattern (PNA) appears in a realistic climatological-mean flow. Influences of the mean flow on the response to tropical heating were also demonstrated by Garcia and Salby (1987). By placing tropical forcing centered at $10^{\circ} \mathrm{S}$ in a January zonally symmetric mean flow, they showed that the responses in the Northern Hemisphere are predominantly extratropical and wavelike. On the contrary, the responses in the Southern Hemisphere are mostly restricted in the low latitudes and are elongated zonally, exhibiting a characteristic similar to equatorial Rossby waves. The equatorial Kelvin waves, although evident, are weak.

Our results seem to be consistent with the numerical studies described above. In this study, the extratropical signals associated with the intraseasonal oscillation are more prominent in the Northern Hemisphere where zonal asymmetry is strong, while the equatorial signals are more prominent in the Southern Hemisphere where the flow is predominantly zonal. The circulation patterns in the Tropics of the Southern Hemisphere are likely to be the direct response to the tropical heating and move eastward coherently with the eastward propagation of tropical convective activity. The circulation patterns in the Northern Hemisphere are the mixture of direct response to the tropical heating and self adjustment between the divergent and rotational flows embedded in Rossby wave-like disturbances. The latter is possibly influenced by the internal dynamics in the extratropics, that will be discussed in the following sections.

\section{Extratropical structure in the Northern Pacific}

The weak wavelike structure emanating from the eastern Indian Ocean into the northern Pacific, shown in Figs. 9a and 9b, appears to be linked to the convective region over the eastern Indian Ocean present dur- 
ing the same period. It develops into a PNA-like structure, which resembles the most unstable mode of the climatological 300-hPa mean flow (Simmons et al. 1983 ). Recent studies (e.g., Zhang 1988; Ferranti et al. 1990 ) found that the adjoint of the PNA-like normal mode is a wavelike structure over the Indochina and India. By placing either an initial vorticity perturbation or a divergence forcing resembling the adjoint mode in a barotropic model linearized about the 300-hPa January climatological flow (Zhang 1988), a wavelike pattern resembling the one in Fig. 9a and $9 \mathrm{~b}$ developed and evolved into the PNA-like modal structure. Although the mode develops rapidly by extracting barotropic energy from the mean flow, the normal mode instability has been found too weak to be responsible for the growth. Instead, nonmodal growth that also extracts energy from the mean flow, seems to be a more plausible mechanism (e.g., Zhang 1988; Ferranti et al. 1990).

The sudden development of the PNA-like structure from the weak wavelike structure exhibits similar characteristics of the model results and theory described above. To examine whether the above mechanism occurs in intraseasonal oscillations, we estimate the kinetic energy conversion from the mean flow to the transient eddies, based on the reconstructed wind anomalies described in the preceding section. The kinetic energy conversion is defined as follows:

$$
\begin{aligned}
C\left(\bar{K}, K^{\prime}\right)= & -\frac{\overline{u^{\prime 2}}}{a \cos \phi} \frac{\partial \bar{u}}{\partial \lambda}-\frac{\overline{u^{\prime} v^{\prime}}}{a} \cos \phi \frac{\partial}{\partial \phi}\left(\frac{\bar{u}}{\cos \phi}\right) \\
& -\frac{\overline{u^{\prime} v^{\prime}}}{a \cos \phi} \frac{\partial \bar{v}}{\partial \lambda}-\frac{\overline{v^{\prime 2}}}{a} \frac{\partial \bar{v}}{\partial \phi}+\overline{v^{\prime 2}} \bar{v} \frac{\tan \phi}{a} .
\end{aligned}
$$

The results are shown in Fig. 11, for day -10 , day 0 , and day 15 . At day -15 (not shown), there is significant positive energy conversion over Indochina but not in the northern Pacific. By day -10 (Fig. 11a), significant positive energy conversion is established both in Indochina and in the central northern Pacific. The distribution of energy conversion is in quadrature with the wavelike pattern in the vorticity field, for example, in Fig. 9b. The positive energy conversion in South Asia and the central northern Pacific reaches its peak value at day 0 . Regions of maximum energy conversion are sandwiched between the east-west elongated circulation dipoles, for example, in Fig. 9d. The derived $E$ vector defined by Hoskins et al. (1983, not shown) point westward, upgradient of the climatological-mean zonal wind speed, indicating a barotropic energy conversion from the mean flow to eddies. Schubert and Park (1991) also concluded that the PNA-like pattern has its main energy source in the middle latitudes. The consistency between our results and the above theory suggests that the weak wavelike structure observed in Fig. 9a, which seems to be forced by the convective activity in the Tropics, may trigger the modal structure (a) day -10

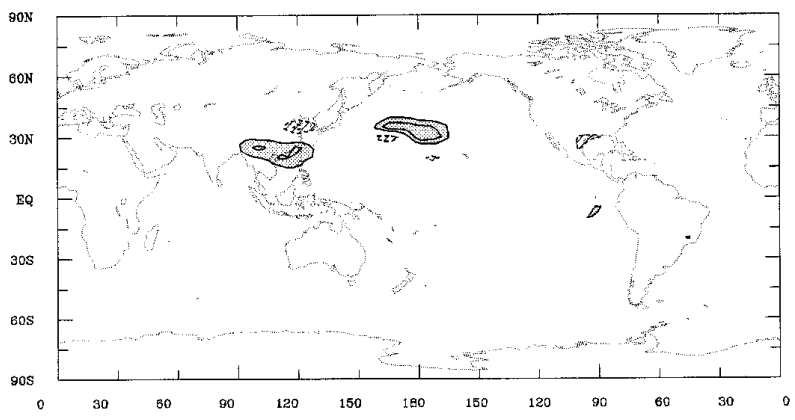

(b) day 0

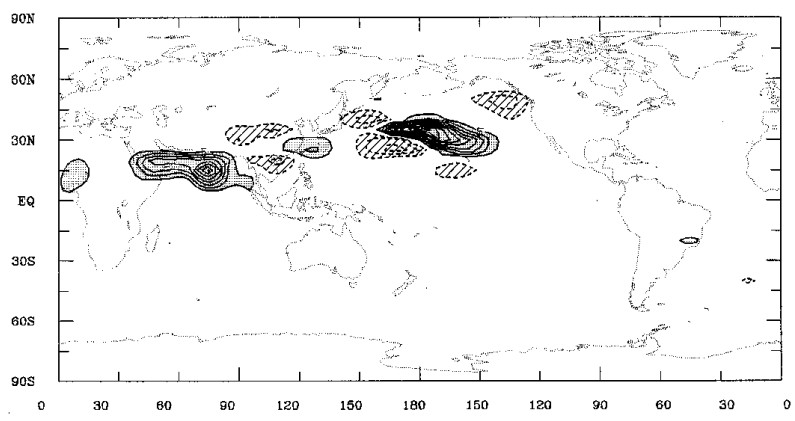

(c) day 15

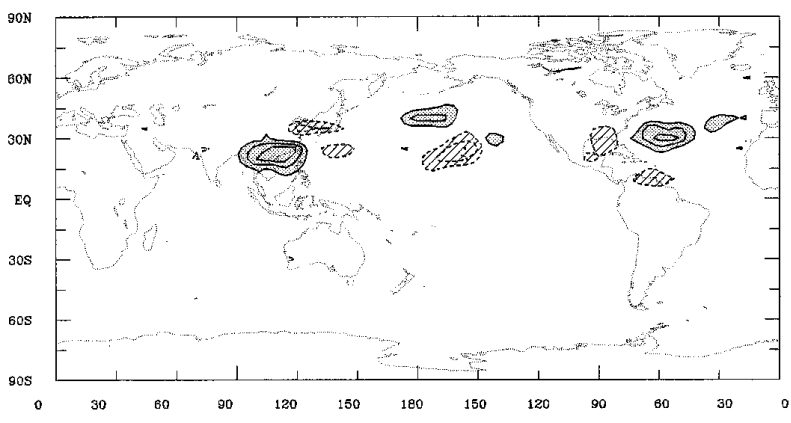

FIG. 11. Kinetic energy conversion rates from mean flow to eddies calculated from the reconstructed wind anomalies at (a) day -10 , (b) day 0 , and (c) day 10. Contour interval is $5 \times 10^{-5} \mathrm{~J} \mathrm{Kg}^{-1} \mathrm{~s}^{-1}$ but the zero value contour is not drawn. Stippling and hatching indicate where the values are greater than $5 \times 10^{-5} \mathrm{~J} \mathrm{Kg}^{-1} \mathrm{~s}^{-1}$ and less than $-5 \times 10^{-5} \mathrm{~J} \mathrm{Kg}^{-1} \mathrm{~s}^{-1}$, respectively.

that grows through barotropic instability. On the other hand, the real contribution of the barotropic energy conversion to the growth of the pattern is not estimated here. A thorough investigation of all forms of enery conversion will be needed to yield a quantitative answer.

Significant energy conversions do not appear in the Atlantic until day 5. By day 10, the energy conversion rate slows down in the Pacific but speeds up in the 
Atlantic. The energy conversion rate in the Atlantic peaks at day 15 (Fig. 11c). The above results show that the largest energy conversions in the Pacific and over South Asia are followed by the largest energy conversion in the Atlantic about 15 days later. The sequence coincides with the abrupt development of local circulation anomalies in these two regions. A close examination of the $200-\mathrm{hPa}$ vorticity pattern from day -5 to day 5 (Figs. 9c,d,e) reveals the existence of a tropical wavetrain that emanates from the tropical Southern Hemisphere near the date line, crosses the equatorial westerly wave duct (Webster and Holton 1982; Hsu and Lin 1992) northeastward into the Caribbean Sea. The structure is also evident in the streamfunction and height fields. The positive correlation region to the north of Brazil later develops into an anomalous circulation in the subtropics of the northern Atlantic. It seems possible that the perturbation associated with the cross-equator wavetrain triggers barotropic instability, leading to the amplification of anomalous circulation in the region.

The PNA-like modal structure, found by Simmons et al. (1983), evolves into a modal structure similar to the Eastern Atlantic pattern (Wallace and Gutzler 1981) through Rossby wave dispersion across North America. A similar evolution is not evident in the sequence shown in Figs. 2 and 9. Although a weak wavelike structure can be seen across North America at day 0, the strongest signals of in situ development in the Atlantic appear to the east of the Caribbean Sea between the equator and $30^{\circ} \mathrm{N}$ (Fig. 9f) and do not have a clear link with the wavelike pattern in the high latitudes.

\section{Meridional propagation}

In the results shown above, zonally symmetric structures are evident during the evolution of intraseasonal oscillation. To examine the evolution of the zonally symmetric structures more closely, we computed lag correlation coefficients between the expansion coefficients of the first OLR vector and the zonal means of various variables. Shown in Figs. 12a,b are lag correlation coefficients for zonally averaged OLR, streamfunction, and zonal wind at 200 and $850 \mathrm{hPa}$. Northward propagation that occurs mainly between the equator and $30^{\circ} \mathrm{N}$ is evident in all three fields. Positive (negative) streamfunction anomalies are accompanied by easterly (westerly) anomalies and positive (negative) OLR anomalies to the south. Standing oscillations are also evident in all three fields. Signals at the equator and in the Southern Hemisphere primarily exhibit the characteristics of standing oscillation with little evidence of meridional propagation. A comparison between Figs. 12 and 2 indicates that the zonally elongated circulation anomalies in Fig. 2 starts to develop when the zonally averaged streamfunction reached its peak at $30^{\circ} \mathrm{N}$.

For the $850-\mathrm{hPa}$ streamfunction and zonal wind fields shown in Figs. 12c,d, northward propagation is evident between the equator and $30^{\circ} \mathrm{N}$ but is much weaker than its counterpart at $200 \mathrm{hPa}$. It is worth noting that northwardly propagating components at 200 and $850 \mathrm{hPa}$ are in phase, indicating an equivalent barotropic vertical structure. A standing oscillation in the northern extratropics in Fig. 12c appears to be the strongest signal at $850 \mathrm{hPa}$. The extratropical standing oscillations at 200 and $850 \mathrm{hPa}$ exhibit a phase lag in such a manner that the 200-hPa pattern leads the 850$\mathrm{hPa}$ pattern by about 10 days.

The above results suggest the possibility of an interaction between zonally symmetric circulation and the eddies during the evolution of intraseasonal oscillations. The northward propagation of the zonally symmetric pattern starts when the perturbations of zonally averaged OLR in the Tropics are the largest, that is also when the convection in the Indian Ocean is either most active or most inactive. The characteristics of the zonally symmetric pattern discussed above are consistent with the findings of previous studies on atmospheric angular momentum. Anderson and Rosen (1983) found that quasi-periodic fluctuation in the atmospheric angular momentum, on the timescale of 40-50 days, is associated with a wavelike pattern in the zonally averaged zonal wind. The pattern also exhibits an equivalent barotropic vertical structure with its largest amplitude near $200 \mathrm{hPa}$, and propagates poleward from the equator to $20^{\circ} \mathrm{N}$ and $20^{\circ} \mathrm{S}$. The propagation is more evident in the Northern Hemisphere. A near standing pattern linked with the propagating feature is also found near $40^{\circ} \mathrm{N}$ in their study. Kang and Lau (1994) and Magaña (1993) reported similar findings. Magaña (1993) further found that the 40 and 50 day oscillations of the globally integrated angular momentum (GAM) are predominantly contributed by fluctuations in the Tropics. The oscillations are highly correlated with tropical convective activity in such a manner that the GAM is maximum when convection strengthens in the western/central Pacific and weakens in the Indian Ocean. The results shown here are consistent with the findings of Magaña (1993). To understand the phenomenon, Anderson and Stevens (1987) analyzed normal modes of a zonally symmetric basic flow and found a northward propagating mode with a period of 30-90 days when the basic flow includes the Hadley circulation. It is possible that the evolution of tropical convective activity associated with intraseasonal oscillation initiates the poleward propagation, by modulating the fluctuation of the Hadley circulation. However, the mechanism that controls the phase-locking between the zonally symmetric component and eddy is not yet understood.

\section{Concluding remarks}

In this study, we reexamine the time evolution of intraseasonal oscillation during northern winter. Characteristics of the circulation pattern documented here 
(a) $200 \mathrm{hPa}[\psi] \&$ [OLR]

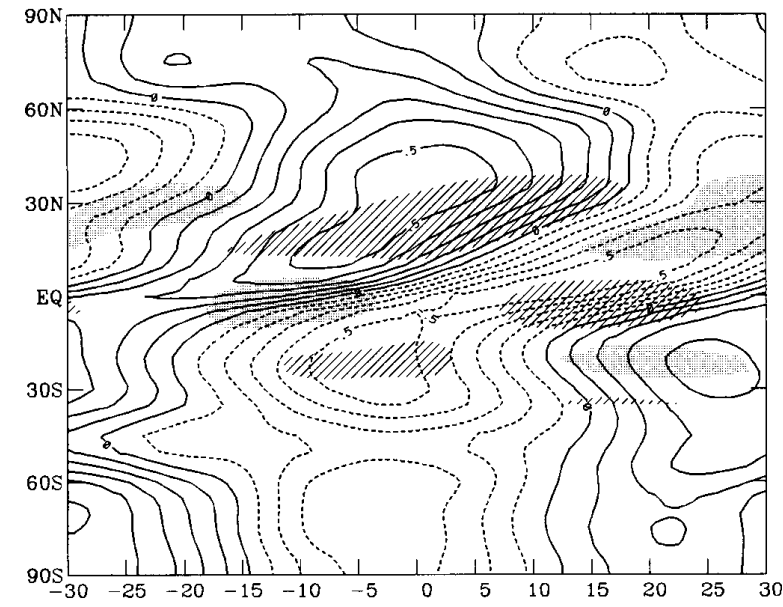

(b) $200 \mathrm{hPa}$ [U] \& [OLR]

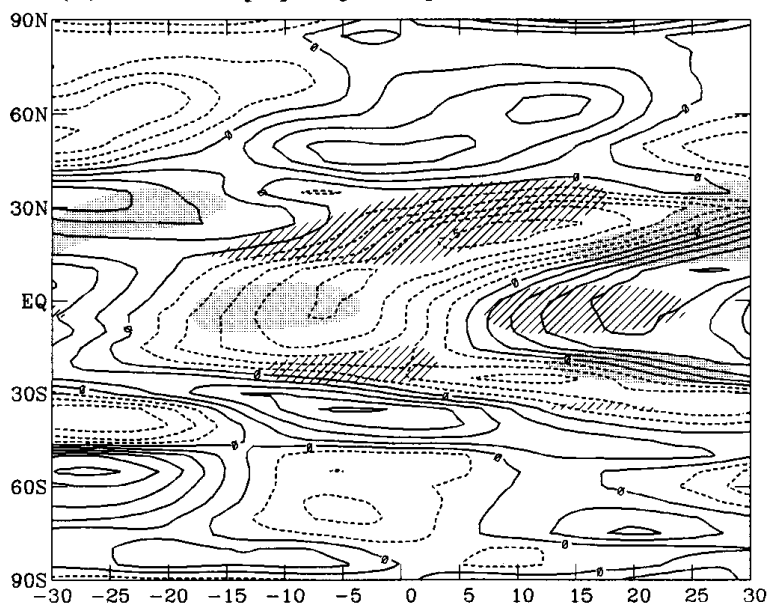

(c) $850 \mathrm{hPa}[\psi] \&[O L R]$

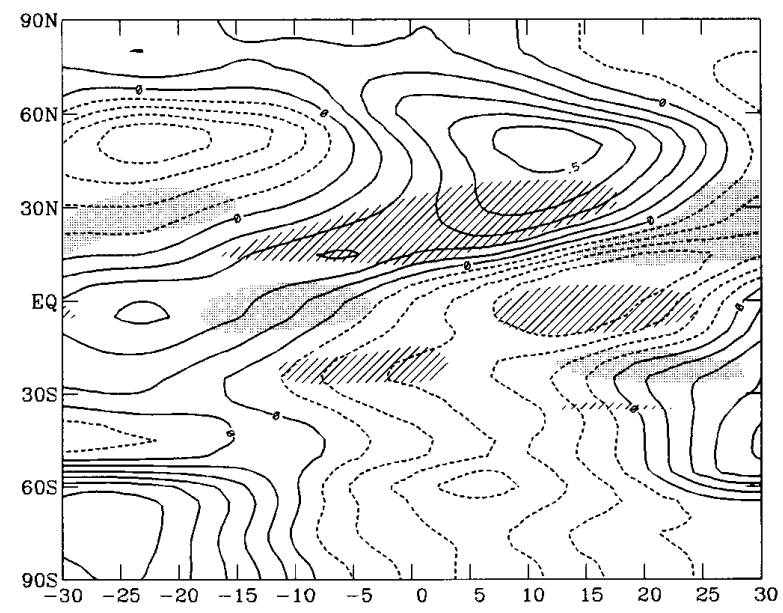

(d) $850 \mathrm{hPa}$ [U] \& [OLR]

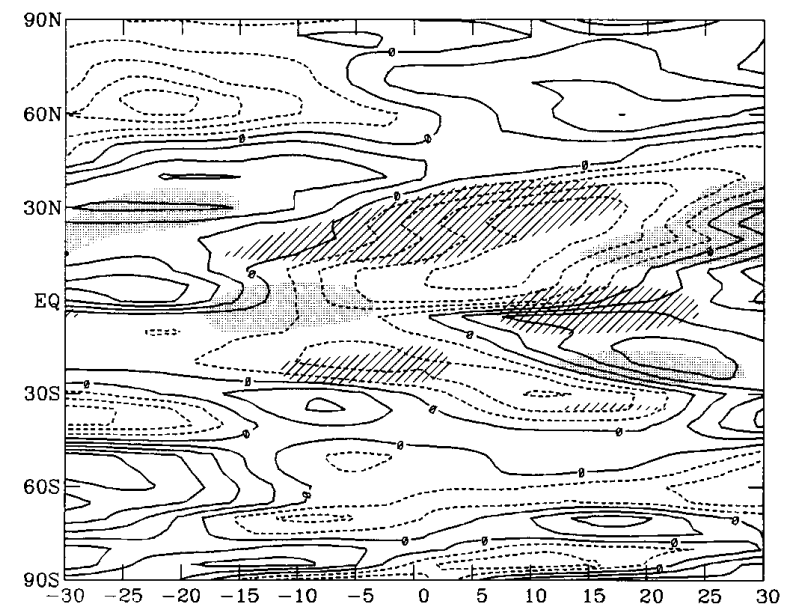

FIG. 12. Hovmöller diagrams of the correlation coefficients between the expansion coefficients of the first OLR vector and the zonally averaged (a) 200-hPa streamfunction, (b) 200-hPa zonal wind, (c) 850-hPa streamfunction, and (d) 850-hPa zonal wind fields from day -30 to day 30 . The contour interval is 0.1 . Stippling and hatching indicate where the correlation coefficients for the zonally averaged OLR are less than -0.2 and greater than 0.2 , respectively.

are consistent with those shown in previous studies, for example, Knutson and Weickmann (1987), and Lau and Chan (1985). However, a careful examination reveals the complexity of the phenomenon that has not been the focus of much discussion in previous studies and deserves more attention. The intraseasonal oscillation includes eastward propagation along the equator, standing oscillations in both the Tropics and the extratropics, and the poleward propagation of a zonally symmetric structure. Significant signals were found in various variables in both the Tropics and the extratropics, consistent with previous studies. Evidence of vigorous tropical-extratropical interaction was also found. Many previous studies have treated the phenomenon as a purely tropical feature and may have missed some important aspects of the intraseasonal oscillation.
The eastward propagation of convective activity was observed from the Indian Ocean to the date line. The corresponding circulation patterns are the anticyclonic and cyclonic circulation couplets located poleward of the active and suppressed tropical convection. Hsu et al. (1990) and Jin and Hoskins (1995) have shown that these circulation couplets can be forced by tropical heating. They also noted that Gill-type response to tropical heating (Gill 1980), derived from a rest basic state, cannot be applied to explain the structure of the observed couplets and their relative position to the heating. Many theories, mostly based on Kelvin-wave CISK, have been proposed to explain the cause of the eastward propagation. In this study, however, we found little evidence of equatorial Kelvin wave, consistent with the findings of Nishi (1989) and Hsu et al. 
(1990). For example, the in-phase relationship between the height and wind fields in a Kelvin wave is not evident in the area where eastward propagation prevails. Furthermore, the amplitudes do not decay rapidly away from the Tropics as the equatorial waves do. Instead, the perturbations are predominantly associated with Rossby wave type circulation in the subtropics. The discrepancies between the observed features and the theories, that were also evident in previous studies, suggest the inadequacy to interpret the intraseasonal oscillation based solely on equatorial wave dynamics.

Besides the eastward propagation, there is a tendency for circulation patterns and tropical convective activities to be amplified in certain regions, indicating the existence of standing oscillations. Signals of large amplitudes are present in both the Tropics and the extratropics. While eastward propagation dominates the evolution of tropical convection and circulation patterns in the low latitudes of the Southern Hemisphere, standing oscillations are the dominant features for circulation patterns in the Northern Hemisphere. Extratropical signals are also much stronger in the Northern Hemisphere than in the Southern Hemisphere. It has been shown in several studies, for example, Sardeshmukh and Hoskins (1988) and Hsu (1994), that remote responses in the subtropics and extratropics of the winter Hemisphere are relatively insensitive to the position of a specified tropical divergence. Jin and Hoskins (1995) also showed that extratropical responses to tropical heating are more rigorous in the Northern Hemisphere than in the Southern Hemisphere during boreal winter. This contrasting behavior seems to result from the different properties of the mean flow in the winter and summer hemisphere and can be explained as follows. The RWS that induces the atmospheric circulation tends to reach its peak value near the core of the jet streams, as long as there exists absolute vorticity advection by divergent winds, or a local divergence anomaly near the relative vorticity maximum. In the winter hemisphere, the relative vorticity and its gradient are very large near the jet streams and thus the Rossby wave source in the extratropics overwhelms the forcing in the Tropics. This effect is less significant in the summer hemisphere where the tropical forcing is not necessarily smaller than its extratropical counterpart, especially in the lower troposphere. It is thus understandable that the largest circulation signals in the Southern Hemisphere are in the tropical region and move eastward along with the tropical convection activity.

It is found in this study that the RWS distribution in an intraseasonal oscillation is dominated by the local divergence effect in the extratropics, instead of by the advection of divergent flows as suggested in Sardeshmukh and Hoskins (1988). The extratropical circulation patterns in the Northern Hemisphere shown here exhibit Rossby wave-like characteristics. The divergence and vorticity fluctuations are in quadrature spa- tially in such a manner that divergence (convergence) anomalies lead positive (negative) vorticity anomalies. The divergence pattern embedded in the wavelike structure, together with the large relative vorticity near the jet stream, contributes significant RWS and overwhelms the contribution of advection effect. Before the abrupt development of the dipole in the northern $\mathrm{Pa}$ cific, a wavelike pattern, which could be a stationary response to the tropical convective activity, emanates from Indochina into the northern Pacific. Its divergence center over Japan is located near the jet core and leads to stationary Rossby wave source. The accompanying vorticity perturbation is a north-south dipole straddling the exit of the Pacific jet stream that is oriented in such manner to roughly balance the RWS through vorticity advection by mean rotational flows. The polarity of the dipole does not change until tropical convection in the western Pacific and the local Hadley circulation switches between its active and suppressed phases. It is suggested that the standing oscillations documented above are partly the manifestation of the extratropical quasi-stationary waves.

One of the most significant features during the evolution is the sudden appearance of a circulation dipole in the northern Pacific, which develops from a wavelike structure emanating from the eastern Indian Ocean into the northern Pacific. A calculation of barotropic energy conversion suggests that the abrupt development of the anomalous circulation can be attributed, at least partially, to the local barotropic energy conversion from the time-mean flow to eddy. The following mechanism is proposed to explain the sudden appearance of the extratropical dipole. The anomalous convective activity in the far western Pacific and eastern Indian Ocean force a weak stationary Rossby wave that propagates into the northern Pacific. The wave, in turn, triggers a PNA-like circulation through barotropic energy conversion from mean flow. The process is consistent with the optimal excitation of normal mode as in Zhang (1988) and Ferranti et al. (1990), among others. It is worth noting that the development of the observed dipole resembles the process simulated in a barotropic model (Zhang 1988). The result implies the difficulty to delineate the relative importance of the tropical forcing and extratropical dynamics. As discussed above, a Rossby wave can be excited by tropical forcing. However, its internal dynamics can dominate the later evolution away from the Tropics. It suggests that tropical forcing alone cannot have excited the circulation features documented in this study. This argument is also implied in many studies of nonmodal dynamics discussed above.

An abrupt development of the circulation pattern, that is also associated with a similar energy conversion process, occurs in the exit region of the Atlantic jet stream. The circulation pattern in the northern Atlantic starts developing 10 days after the circulation pattern in the northern Pacific reaching its mature stage. In be- 
tween, a wavelike structure in the upper troposphere emanates from the Tropics of the southern central Pacific, crosses the westerly wave duct in the Tropics of the eastern Pacific, and propagates into the Caribbean Sea. It is likely that the perturbation associated with the wave pattern initiates the energy conversion, leading to the amplification of the circulation pattern. The proposed triggering effect has not been reported in any numerical or theoretical studies.

Another interesting feature is the northward propagation of a zonally symmetric pattern. It occurs when the tropical convection in the Indian Ocean reaches its peak in the active and suppressed phases and when the zonally averaged OLR anomalies have their extreme values. To the best of our knowledge, the phenomenon has not been well understood. Interestingly, the feature bears the characteristics similar to the normal mode of an intraseasonal timescale in a zonally symmetric mean flow that includes the Hadley circulation (Anderson and Stevens 1987). The zonally symmetric pattern, which is also associated with the fluctuations of atmospheric angular momentum (e.g., Kang and Lau 1994; Magaña 1993), is phase locked with the eddy components and tropical convection activity. The interaction between mean flow and waves seems to be an important aspect of the intraseasonal oscillation that has not yet been carefully examined and deserves further study.

The study suggests that the intraseasonal oscillation is a global phenomenon and cannot be treated either as a purely tropical or a purely extratropical feature. The phenomenon is much more complicated than what has been suggested by many empirical and theoretical studies that emphasized tropical features alone. The equatorial wave mechanism may explain some characteristics of the phenomenon, for example, the eastward movement of the tropical convection activity. However, it fails to explain significant circulation features in the subtropics and extratropics. Evidently, theories based mainly on equatorial wave dynamics can only partially explain the evolution of the intraseasonal oscillation. Mechanisms considering tropical-extratropical interactions, extratropical internal dynamics, and equatorial wave dynamics should be integrated to better understand the phenomenon.

Acknowledgments. This work was supported by the National Science Council of Taiwan under Grant NSC 82-0202-M002-074.

\section{REFERENCES}

Anderson, J. R., and R. D. Rosen, 1983: The latitude-height structure of 40-50 day variations in atmospheric angular momentum. $J$. Atmos. Sci., 40, 1584-1591.

_ , and D. Stevens, 1987: The presence of linear wavelike modes in a zonally symmetric model of the tropical atmosphere. $J$. Atmos. Sci., 44, 2115-2127.

Bladé, I., and D. L. Hartmann, 1993: Tropical intraseasonal oscillations in a simple nonlinear model. J. Atmos. Sci., 50, 2922 2939.
Bretherton, C. S., C. S. Smith, and J. M. Wallace, 1992: An intercomparison of methods for finding coupled patterns in climate data. J. Climate, 5, 541-560.

Chang, C.-P., 1977: Viscous internal gravity waves and low-frequency oscillations in the tropics. J. Atmos. Sci., 34, 901-910. , and H. Lim, 1988: Kelvin wave-CISK: A possible mechanism for the 30-50 day oscillations. J. Atmos. Sci., 45, 1709-1719.

Chen, W. Y., 1982: Fluctuations in Northern Hemisphere $700 \mathrm{mb}$ height field associated with the Southern Oscillation. Mon. Wea. Rev., 110, 808-823.

Emanuel, E. A., 1987: An air-sea interaction model of intraseasonal oscillations in the tropics. J. Atmos. Sci., 44, 2324-2340.

Ferranti, L., T. N. Palmer, F. Molteni, and E. Klinker, 1990: Tropicalextratropical interaction associated with the 30-60 day oscillation and its impact on medium and extended range prediction. J. Atmos. Sci., 47, 2177-2199.

Garcia, R. R., and M. L. Salby, 1987: Transient response to localized episodic heating in the Tropics. Part II: Far field behavior. $J$. Atmos. Sci., 44, 499-530.

Ghil, M., and K. Mo, 1991a: Intraseasonal oscillations in the global atmosphere. Part I: Northern Hemisphere and Tropics. J. Atmos. Sci., 48, 752-779.

$\longrightarrow$, and - 1991b: Intraseasonal oscillations in the global atmosphere. Part II: Southern Hemisphere. J. Atmos. Sci., 48, $780-790$.

Gill, A. E., 1980: Some simple solutions for heat-induced tropical circulation. Quart. J. Roy. Meteor. Soc., 106, 447-462.

Hartmann, D. L., and J. R. Gross, 1988: Seasonal variability of the 40-50 day oscillation in wind and rainfall in the tropics. $J$. Atmos. Sci., 45, 2680-2702.

Hendon, H. H., 1986: Streamfunction and velocity potential representation of equatorial trapped waves. J. Atmos. Sci., 43, $3038-$ 3042.

-, and M. L. Salby, 1994: The life cycle of the Madden-Julian oscillation. J. Atmos. Sci., 51, 2225-2237.

Hsu, H.-H., 1994: Relationship between tropical heating and global circulation: Interannual variability. J. Geophys. Res., 99, $10473-10489$.

— streamfunction field during the Northern Hemisphere winter. Mon. Wea. Rev., 120, 1169-1190.

, B. J. Hoskins, and F.-F. Jin, 1990: The 1985/86 intraseasonal oscillation and the role of the extratropics. J. Atmos. Sci., 47, 832-839.

Hu, Q., and D. R. Randall, 1994: Low-frequency oscillations in radiative-convective systems. J. Atmos. Sci., 51, 10891099.

Jin, F., and B. J. Hoskins, 1995: The direct response to tropical heating in a baroclinic atmosphere. J. Atmos. Sci., 52, 307-319.

Kang, I.-S., and K.-M. Lau, 1994: Principal modes of atmospheric circulation anomalies associated with global angular momentum fluctuations. J. Atmos. Sci., 51, 1194-1205.

Kiladis, G. N., and K. M. Weickmann, 1992: Extratropical forcing of tropical Pacific convection during northern winter. Mon. Wea. Rev., 120, 1924-1938.

Knutson, T. R., and K. M. Weickmann, 1987: The 30-60 day atmospheric oscillations: Composite life cycles of convection and circulation anomalies. Mon. Wea. Rev., 115, 1407-1436.

Lau, K.-M., and P. H. Chan, 1985: Aspects of the 40-50 day oscillation during the Northern winter as inferred from outgoing longwave radiation. Mon. Wea. Rev., 113, 1889-1909.

_ , and T. J. Phillips, 1986: Coherent fluctuations of extratropical geopotential height and tropical convection in intraseasonal time scales. J. Atmos. Sci., 43, 1164-1181.

$\longrightarrow$, and L. Peng, 1987: Origin of low-frequency (intraseasonal) oscillations in the tropical atmosphere. Part I: Basic theory. $J$. Atmos. Sci., 44, 950-972.

Lau, N.-C., I. M. Held, and J. D. Neelin, 1988: The Madden-Julian oscillation in an idealized general circulation model. J. Atmos. Sci., 45, 3810-3832. 
Madden, R. A., and P. R. Julian, 1971: Detection of a 40-50 day oscillation in the zonal wind in the tropical Pacific. J. Atmos. Sci., 28, 702-708.

, and - 1972: Description of global-scale circulation cells in the tropics with a 40-50 day period. J. Atmos. Sci., 29, 1109-1123.

Magaña, V., 1993: The 40- and 50-day oscillations in atmospheric angular momentum at various latitudes. J. Geophys. Res., 98(D6), $10441-10450$.

Matsuno, T., 1966: Quasi-geostrophic motions in the equatorial area. J. Meteor. Soc. Japan, 44, 25-42.

Neelin, J. D., I. M. Held, and K. H. Cook, 1987: Evaporation-wind feedback and low-frequency variability in the tropical atmosphere. J. Atmos. Sci., 44, 2341-2348.

Nishi, N., 1989: Observational study on the 30-60 day variations in the geopotential and temperature fields in the equatorial region. J. Meteor. Soc. Japan, 67, 187-203.

Park, C.-K., and S. D. Schubert, 1993: Remotely forced intraseasonal oscillations over the tropical Atlantic. J. Atmos. Sci., 50, 89-103.

Salby, M., R. Garcia, and H. Hendon, 1994: Planetary circulations in the presence of climatological and wave-induced heating. J. Atmos. Sci., 51, 2344-2367.

Sardeshmukh, P. D., and B. J. Hoskins, 1984: Spatial smoothing on the sphere. Mon. Wea. Rev., 112, 2524-2529.

- and — 1988: The generation of global rotational flow by steady idealized tropical divergence. J. Atmos. Sci., 45, 1228-1251.

Schubert, S. D., and C.-K. Park, 1991: Low-frequency intraseasonal tropical-extratropical interactions. J. Atmos. Sci., 48, 629-650.

Simmons, A. J., J. M. Wallace, and G. W. Branstator, 1983: Barotropic wave propagation and instability and atmospheric teleconnection patterns. J. Atmos. Sci., 40, 363-392.
Sui, C.-H., and K.-M. Lau, 1989: Origin of low-frequency (intraseasonal) oscillations in the tropical atmosphere. Part II Structure and propagation of mobile wave-CISK modes and their modification by lower boundary forcings. J. Atmos. Sci. 46, 37-56.

Ting, M., and P. D. Sardeshmukh, 1993: Factors determining the extratropical response to equatorial diabatic heating anomalies. J. Atmos. Sci., 50, 907-918.

Wallace, J. M., and D. S. Gutzler, 1981: Teleconnections in the geopotential height field during the Northern Hemisphere winter. Mon. Wea. Rev., 109, 784-812.

Wang, B., 1988: Dynamics of tropical low-frequency waves: An analysis of the moist Kelvin wave. J. Atmos. Sci., 45, $2051-$ 2065.

, and H. Rui, 1990: Dynamics of the coupled moist KelvinRossby wave on an equatorial $\beta$ plane. J. Atmos. Sci., 47, 397413.

Webster, P. J., and J. R. Holton, 1982: Cross-equatorial response to middle-latitude forcing in zonally varying basic state. J. Atmos. Sci., 39, 722-733.

Weickmann, K. M., and S. J. S. Khalsa, 1990: The shift of convection from the Indian Ocean to the western Pacific Ocean during a 30-60 day oscillation. Mon. Wea. Rev., 118, 964-978.

Wright, P. B., J. M. Wallace, T. P. Mitchell, and C. Deser, 1988: Correlation structure of the El Niño/Southern Oscillation phenomenon. J. Climate, 1, 609-625.

Zhang, Z., 1988: The linear study of zonally asymmetric barotropic flows. Ph.D. thesis, University of Reading, 178 pp. [Available from The British Library, Document Supply Centre, Boston Spa, Wetherby, West Yorkshire, United Kingdom.] 